\title{
A!
}

This is an electronic reprint of the original article.

This reprint may differ from the original in pagination and typographic detail.

Cheng, Qiang; Ahmad, Zeeshan; Kaario, Ossi; Larmi, Martti

\section{Cycle-to-cycle variations of dual-fuel combustion in an optically accessible engine}

\section{Published in:}

Applied Energy

DOI:

10.1016/j.apenergy.2019.113611

Published: 02/08/2019

Document Version

Peer reviewed version

Published under the following license:

CC BY-NC-ND

Please cite the original version:

Cheng, Q., Ahmad, Z., Kaario, O., \& Larmi, M. (2019). Cycle-to-cycle variations of dual-fuel combustion in an optically accessible engine. Applied Energy, 254, [113611]. https://doi.org/10.1016/j.apenergy.2019.113611

This material is protected by copyright and other intellectual property rights, and duplication or sale of all or part of any of the repository collections is not permitted, except that material may be duplicated by you for your research use or educational purposes in electronic or print form. You must obtain permission for any other use. Electronic or print copies may not be offered, whether for sale or otherwise to anyone who is not an authorised user. 


\title{
Cycle-to-Cycle Variations of Dual-Fuel Combustion in an Optically Accessible Engine
}

\author{
Qiang Cheng*, Zeeshan Ahmad, Ossi Kaario, Larmi Martti
}

Aalto University, School of Engineering, Department of Mechanical Engineering, 00076 Aalto, Finland

\begin{abstract}
Cyclic variations constitute an inherent consequence of the flow, thermal and concentration field variations between cycles. They are understood to lead to lower efficiency and higher emissions. The current investigation aims to evaluate the cycle-to-cycle variations (CCVs) based on 2D visualization and cylinder pressure in an optically accessible heavy-duty engine fueled with methane (main fuel) and diesel (pilot fuel). A high-speed color camera is employed to measure the combustion behavior based on natural luminosity (NL). Proper orthogonal decomposition (POD) is applied to reconstruct and analyze the images. The POD-based coefficient of variation $(\mathrm{COV})$ is implemented to evaluate the cyclic variability, along with the pressure-based and global intensity-based COV. This coefficient is then adopted to discriminate the coherent and incoherent parts from the fluctuations in the luminosity field. The POD-based and global intensity-based COV presents the variations in the luminosity field, which can provide information on chemical kinetics, while pressure-based COV provides a general description of the cyclic fluctuation of thermodynamics. To extract more information from the NL images, the color-intensity COV analysis based on the intensity separated from RGB channels is adopted to estimate the CCVs from the aspect of spectral emissions (excited and ionized radicals in the flame). Finally, the effects of methane lambda, pilot fuel rate and charge air temperature on the CCVs were analyzed systematically. The results revealed that richer methane conditions has an inhibitive effect on the CCVs. The appearance of the CCVs were determined by the ignition characteristics of the pilot fuel. A critical point was found in charge air temperature, when the charge air temperature lower than the critical point, the increase of the charge air temperature has a promotive effect on the CCVs; after that, it has an inhibitive effect on the CCVs.
\end{abstract}

Keywords: Cycle-to-Cycle variations, Dual fuel engine, Optically accessible engine, Natural luminosity, POD

\section{Introduction}

$\mathrm{CCVs}$ in reciprocating internal combustion engines are widely known as an inherent consequence of the flow field, thermal field and concentration field variations between cycles [1,2]. There is a general understanding that cyclic variations lead to lower efficiency and higher emissions [3, 4]. Concerns about $\mathrm{CCVs}$ are highly relevant today because economic and regulatory pressures are pushing engine manufacturers to redesign engines that are particularly prone to this problem [5].

$\mathrm{CCVs}$ are of concern in spark ignition (SI) engines due to the spatial mixture in-homogeneities, which are caused by variations in mixture motion, cyclic variations in the local equivalence ratio and mixture composition near the spark plug [6]. These variations can lead to differences in combustion speed or local end-gas autoignition [7,8]. Extensive research has been conducted on CCVs and combustion stabilities in the past using experimental [9-11] and numerical approaches [12-15], and the possible sources of CCVs in spark ignition engine are considered to be well understood [16].

Typically, significant CCVs are less common in conventional compression ignition (CI) diesel engines, due to the nature of dominantly non-premixed CI combustion [6]. However, CI engine may also exhibit cyclic variabilities, and the root cause of these variabilities have usually been connected to instabilities in the fuel injection system (e.g., the shoot-to-shoot and hole-to-hole variations) or to prolonged ignition delay. [17-19]. These findings of CCVs analysises from the literatures are also suitable to dual fuel (DF) engines due to the similar working principle of DF and CI engines. Additionally, the short pulse of the pilot fuel injection leads to more instabilities in mass flow rate and spray propagation. Thus, DF engines 
fueled with natural gas (NG) and pilot diesel appear to be more prone to cyclic variability than conventional CI diesel engines. Even though the possible sources of CCVs of DF engines are well comprehended, and can be connected to the instabilities in the pilot fuel injection system, variation in the stratification of gaseous fuel and prolonged ignition delay [20] and the relative importance of these factors still remains underexamined.

In terms of the significance of cyclic variations in engine performance, numerous studies have concentrated on mechanisms and control strategies on CCVs in terms of SI [21-23], CI [6, 24], and homogeneous charge compression ignition (HCCI) [25-27] engines. However, few analysises have been reported on the CCVs of DF engines [28-31]. The combustion process in DF engines fueled with diesel (pilot) and natural gas (main) is more complicate than either SI or CI engines, which combined diffusion combustion during pilot ignition (like in a $\mathrm{CI}$ engine) and premixed combustion during main combustion (like in a SI engine). Therefore, CCVs in dual fuel engines are more prone than in SI and $\mathrm{CI}$ engines. The root cause of the CCVs in DF engines has usually been related to non-optimal performance of the diesel injection system (variability in diesel injection pressure, mass flow rate, opening delay, nozzle hole-to-hole variability in diesel injected) $[18,19,32]$, to the amount of trapped NG, stratification of NG in cylinder, mixture movement and to the operating and boundary conditions (charge air pressure and temperature). All these potentially affect the igntion, flame propagation, heat release and emission of the combustion processes and thus lead to higher CCVs than in conventional (SI and $\mathrm{CI}$ ) engines.

To gain more insight into the CCVs in DF engines, a POD method was implemented to reconstruct and analyze the images in luminosity field, along with the cylinder pressure. POD is one of the multivariable statistical methods originating in obtaining a compact representation of a high-dimensional data [33], which can be applied to acquire CCV information from 2D visualization [11,23]. Recent studies show that measurement of light emission based on natural luminosity during the combustion process also carry information on CCV phenomena, which can occur in all forms in engines [34]. Bizon et al. [35-37] presented a POD-based approach to analyze the combustion-related luminosity taken in both SI and CI optically accessible engines, and POD modes were discriminated by means of normality tests, to separate the mean from the coherent and incoherent parts in luminosity field, in a non-truncated representation of the data. Charalambides, et al. [38] applied POD to investigate the temporal and spatial repeatablility of the autoignition front and compare these characteristics to the considered scenarios in a optical engine running in HCCI combustion mode. The conclusion based on POD analysis of the timeresolved flame images presented that the appearance of inhomogeneity either in the temperature or the mixture fraction distribution increases the probability of random combustion during the very early stages of flame development. This phenonmenon is also related to the fluctuation of heat release. These authors implemented POD to the luminosity field with high-speed imaging to analyze the combustion process in both SI and CI engines [35]. The fluctuations in luminosity field can be observed in different POD modes to estimate the repeatablility of the flame structure and intensity. However, the relationship of CCVs between combustion luminosity field and thermodynamics has been still rarely reported. Therefore, it is necessary to implement an analysis technique to quantitatively address the cyclic variabilities in the luminosity (especially its temporal and spatial repeatability) and thermodynamics fields systematically.

The scope of present investigation is to analyze CCVs systematically in an optically accessible DF engine with a high-speed color camera. A statistical POD method is introduced to discover interdependencies within the flame luminosity field. The coherent and incoherent parts in fluctuations are reconstructed to capture information about the underlying turbulent flow. The CCVs based on the global intensity and color intensity (RGB color in color camera channels) are impleted to estimate the $\mathrm{CCVs}$ in intensity field and emission spectrum of radicals during combustion. The CCVs based on timeresolved cylinder pressure is employed to estimate the cyclic variabilities in thermodynamics. To enhance the understanding of the sources of CCVs in DF engines, the $\mathrm{CH} 4$ lambda $\left(\lambda_{\mathrm{CH} 4}\right)$, injection 
(pilot and main) and charge air temperature ( $\left.T_{\text {air }}\right)$ parameter variants are adopted to analyze the CCVs under different engine operating conditions.

\begin{tabular}{|c|c|c|c|}
\hline \multicolumn{4}{|l|}{ Nomenclature } \\
\hline ATDC & After top dead center & $c_{i}^{\prime}$ & $\begin{array}{l}\text { Pair wise uncorrelated random } \\
\text { variables }\end{array}$ \\
\hline $\mathrm{C}$ & Correlation matrix & $I C O V_{k, t}$ & Coefficient of variation of intensity \\
\hline CAD & Crank angle degree & $\operatorname{Int}_{k, t}$ & The $k$ th snapshot at crank angle $t$. \\
\hline $\mathrm{CCVs}$ & Cycle-to-Cycle Variations & $\overline{\operatorname{Int}}_{k, t}$ & $\begin{array}{l}\text { The averaged global integrated } \\
\text { intensity at crank angle } t \text {. }\end{array}$ \\
\hline CI & Compression ignition & $\bar{P}_{k, t}$ & The average pressure at crank angle $t$ \\
\hline CMOS & $\begin{array}{l}\text { Complementary Metal Oxide } \\
\text { Semiconductor }\end{array}$ & $P C O V_{k, t}$ & $\begin{array}{l}\text { Coefficient of variation of cylinder } \\
\text { pressure }\end{array}$ \\
\hline $\mathrm{COV}$ & Coefficient of variation & $u^{\prime}$ & Fluctuation in luminosity field \\
\hline DF & Dual fuel & $u_{c o h}^{\prime}$ & Coherent part \\
\hline EHVA & $\begin{array}{l}\text { electrohydraulic valve } \\
\text { actuator }\end{array}$ & $u_{k}$ & Snapshot image \\
\hline $\mathrm{HCCI}$ & $\begin{array}{l}\text { homogenous charge } \\
\text { compression ignition }\end{array}$ & $u_{\text {incoh }}^{\prime}$ & Incoherent part \\
\hline HRR & Heat Release Rate & $t$ & Time \\
\hline IDT & Ignition delay timing & $t_{\text {pilot }}$ & Pilot fuel duration \\
\hline NG & Natural gas & $T_{\text {air }}$ & Charge air temperature \\
\hline NL & Natural luminosity & Greek syn & bols \\
\hline POD & $\begin{array}{ll}\text { Proper } & \text { orthogonal } \\
\text { decomposition } & \end{array}$ & $\lambda_{\mathrm{CH} 4}$ & Methane lambda \\
\hline SOI & Start of injection & $\varphi_{m}(x)$ & Basis function \\
\hline$S$ & Gaussian coefficient & $\Psi$ & Eigenvectors \\
\hline SI & Spark ignition & $\begin{array}{c}\gamma_{1} \\
\beta_{2} \\
\sigma_{i} \\
\Psi_{m k}\end{array}$ & $\begin{array}{l}\text { Skewness } \\
\text { Kurtosis } \\
\text { Standard deviation } \\
\text { Corresponding coefficients }\end{array}$ \\
\hline
\end{tabular}

\section{Experimental Apparatus}

\subsection{Optically Accessible Engine}

The optical engine layout is sketched in Fig.1(a), and the engine specifications are detailed in Table 1. The optical single-cylinder engine is variant of an AGCO 84AWI 6-cylinder common rail diesel engine. It is a fully flexible research engine, which provides possibilities to freely vary the critical physical variables that could otherwise be restricted in normal engine operations. An electrohydraulic valve actuator (EHVA) system is employed for a camshaft-less gas exchange system in this optical engine setup, and the fully flexible variable valve actuation system allows controlling the valve lift and timing simultaneously. A Bowditch piston is applied to provide optical access to the combustion chamber. A Kistler 6125 piezoelectric transducer is adopted to measure pressure in cylinder, and the data are recorded at a resolution of $0.2^{\circ}$ crank angle. A common rail fuel injection system controlled by a Labview system provids the ability to control the injection timing and the quantity of the injected fuel. Fig.1(b) provides the geometry diamension of the optical pistion head at TDC (left), location of inlet and exhaust valves at bottom view (right) and location of the spray (right). The swirl direction in the cylinder also marked in Fig.1(b). 


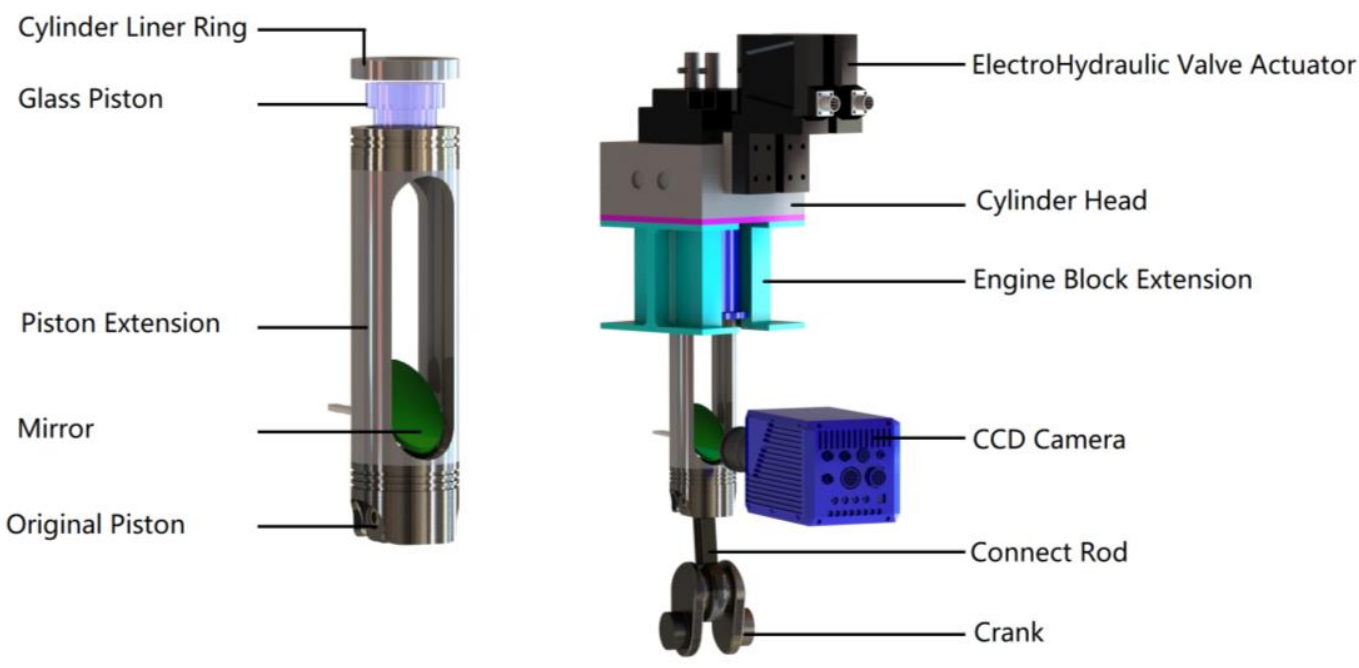

(a)
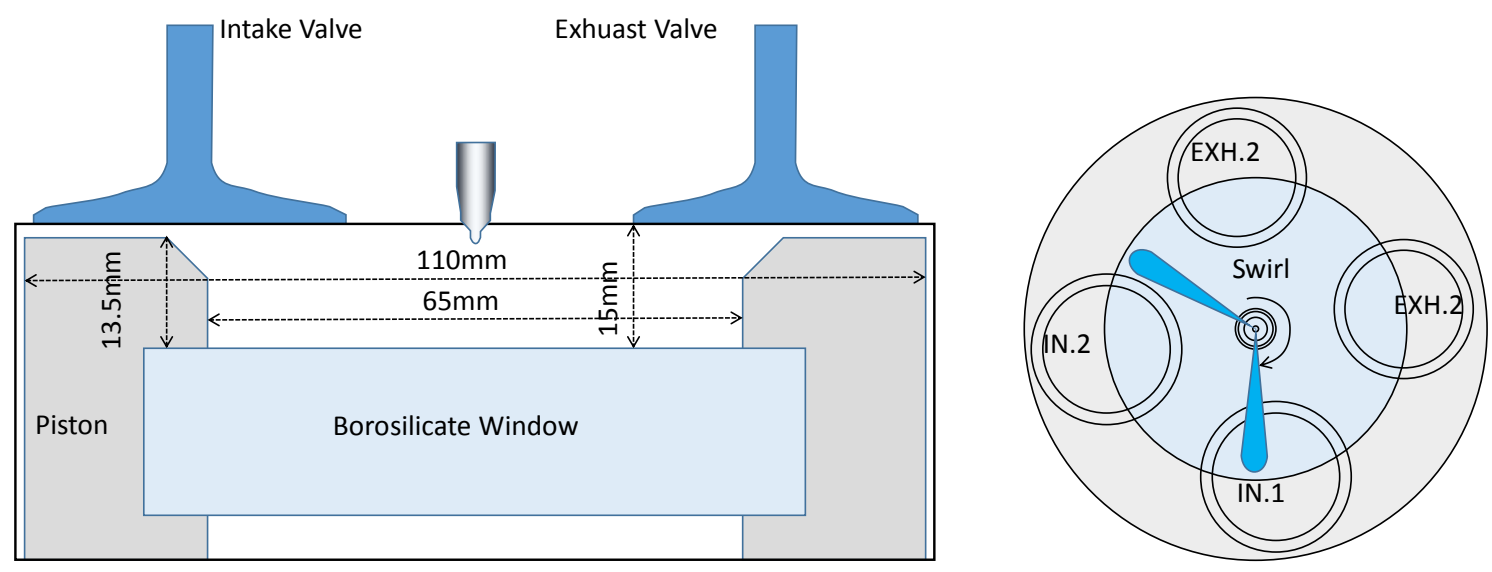

(b)

Fig. 1 (a) Bowditch-type optical engine with details of the piston elongation assembly; (b) dimension of the optical piston head, valve position, swirl direction and spray location.

Table. 1 Engine specifications

\begin{tabular}{l|l}
\hline Engine type & $4-$ Stroke diesel single-cylinder \\
\hline Engine speed & $1400 \mathrm{rpm}$ \\
\hline Bore & $111 \mathrm{~mm}$ \\
\hline Stroke & $145 \mathrm{~mm}$ \\
\hline Swept volume & $842 \mathrm{~cm}^{3}$ \\
\hline Combustion bowl & $19.7 \mathrm{~cm}^{3}$ \\
\hline Vol. compression ratio & $17.9: 1$ \\
\hline Swirl Ratio & 2.7 \\
\hline
\end{tabular}

\subsection{Fuel injection system}

A special multi-fuel injection system was developed to perform dual-fuel engine experiments on both liquid and gaseous fuels. Two unique systems are included: 1) a common-rail injection system, with an asymmetric two-hole (modified from a 9-hole symmetric injector with $120^{\circ}$ ) solenoid injector was applied to pilot fuel injection. and 2) a gaseous port fuel injection system with two gas injectors mounted 
at the manifold near the air intake valve, providing the primary gaseous fuel, namely methane. The specifications of the pilot diesel injector and gaseous port injectors are reported in Table. 2.

Table. 2 Common rail and gas injector specifications

\subsection{Engine operating conditions}

\begin{tabular}{l|l}
\hline Injector type & Bosch CNR13-20 \\
\hline Number of holes & 2 (asymmetric) \\
\hline Include Angle & $148^{\circ}$ \\
\hline Hole diameter & $0.138 \mathrm{~mm}$ \\
\hline Injection pressure & $870 \mathrm{bar}$ \\
\hline Injection timing & 15 BTDC \\
\hline Gas injector & EG2000 gas Injectors \\
\hline Gas injector number & 2 \\
\hline
\end{tabular}

The aim of this investigation is to assess the effects of $\mathrm{CH} 4$ lambda $\left(\lambda_{\mathrm{CH} 4}\right)$, pilot fuel duration $\left(t_{\text {pilot }}\right)$ and charge air temperature $\left(T_{\text {air }}\right)$ on CCVs in dual-fuel combustion. In order to observe these effects, the dual-fuel optical engine was run at middle load $\sim 10$ bar IMEP, charge air pressure 1.1 bar, pilot injection pressure 870 bar and engine speed $1400 \mathrm{rpm}$. A skip-fire strategy was implemented due to the limitations of the mechanical properties of the optical window. A total of 150 cycles for each test point with 22 fired-cycles were recorded to analyze the CCVs. High-purity methane was fueled as primary fuel, and the pilot was fueled with commercial diesel fuel (EN590). Two gas injectors were applied to inject $\mathrm{CH} 4$ into intake air manifold with pressure 3.6 bar at -365 CAD ATDC. The $\lambda_{\mathrm{CH} 4}$ was controlled by the mass flow rate of methane and charge air, and the charge air mass flow rate was stabilized with PID control. The methane-air mixture was inducted into the cylinder through the intake valves along with the intake air. A two-hole solenoid diesel injector injected the pilot fuel into the cylinder at SOI = -15 CAD ATDC. Table 3 outlines the test parameters for the study of the effect of methane lambda, pilot fuel ratio and charge air temperature on dual-fuel combustion. Case A was defined as the effect of $\lambda_{\mathrm{CH} 4}$ on $\mathrm{CCVs}, \lambda_{\mathrm{CH} 4}$ was varied from 2.0 to 1.6 , while keeping $t_{\text {pilot }}$ constant. This resulted in different total energy in the system during combustion. Case B examined the effects of the pilot fuel ratio on CCVs, $t_{\text {pilot }}$ adjusted from $0.45 \mathrm{~ms}$ to $0.7 \mathrm{~ms}$, while keeping $\lambda_{\mathrm{CH} 4}=2.0$. In this case, the injection pressure was kept constant with 870 bar, and the corresponding mass flow rate of the pilot diesel can be seen in Table 3. Case $\mathrm{C}$ was concentrated on the effect of charge air temperature on the CCVs of dual-fuel combustion, the $T_{\text {air }}$ was varied from $298 \mathrm{~K}$ to $328 \mathrm{~K}$, while keeping $\lambda_{\mathrm{CH}_{4}}=2.0$ and $t_{\text {pilot }}=0.45 \mathrm{~ms}$. In order to keep the $\lambda_{\mathrm{CH} 4}$ constant, the mass flow rate of the charge air in Case $\mathrm{C}$ was accurately controlled with a PID module. The engine operating conditions for all the cases are shown in Table 3.

Table 3. Engine operating conditions

\begin{tabular}{l|l|l|l|l|l|l|l|l|l}
\hline & \multicolumn{3}{|c|}{ Case A } & \multicolumn{3}{c|}{ Case B } & \multicolumn{3}{c}{ Case C } \\
\hline$\dot{m}_{\text {air, }}, \mathrm{kg} / \mathrm{h}$ & 55.6 & 55.6 & 55.6 & 55.6 & 55.6 & 55.6 & 55.6 & 55.6 & 55.6 \\
\hline$\lambda_{\mathrm{CH} 4}$ & 2.0 & 1.8 & 1.6 & 2.0 & 2.0 & 2.0 & 2.0 & 2.0 & 2.0 \\
\hline$\dot{m}_{\mathrm{CH} 4}, \mathrm{~kg} / \mathrm{h}$ & 1.63 & 1.82 & 2.04 & 1.63 & 1.63 & 1.63 & 1.63 & 1.63 & 1.63 \\
\hline$t_{\text {pilot }}, \mathrm{ms}$ & 0.45 & 0.45 & 0.45 & 0.45 & 0.6 & 0.7 & 0.45 & 0.45 & 0.45 \\
\hline$T_{\text {air, }}, \mathrm{K}$ & 298 & 298 & 298 & 298 & 298 & 298 & 298 & 318 & 328 \\
\hline
\end{tabular}

\subsection{Fuel Properties}

The standard EN590 was used as a pilot fuel, which provided a strong benchmark. The methane was provided by AGA Industial Gases (Finland) with purity of $99.9 \%$. General properties of the methane and EN590 are listed in Table 4.

\begin{tabular}{l|l|l|l}
\hline Iterms & Unit & EN590 & Mehtane \\
\hline
\end{tabular}




\begin{tabular}{l|l|l|l}
\hline Molecular formula & & $\mathrm{C}_{10} \mathrm{H}_{20}$ to $\mathrm{C}_{15} \mathrm{H}_{28}$ & $\mathrm{CH}_{4}$ \\
\hline Lower heating value & $\mathrm{MJ} / \mathrm{kg}$ & $\approx 43.1$ & 50 \\
\hline Cetane Number & & 52.6 & 0 \\
\hline Stoichiometric air-fuel ratio & & 14.5 & 17.19 \\
\hline Density at $15^{\circ}, 1 \mathrm{~atm}$ & $\mathrm{~kg} / \mathrm{m}^{3}$ & $820-845$ & 0.656 \\
\hline $\mathrm{H} / \mathrm{C}$ ratio & $\mathrm{mole} / \mathrm{mole}$ & 1.91 & 4 \\
\hline Viscosity at $40^{\circ}$ & $\mathrm{mm}^{2} / \mathrm{s}$ & $2.0-4.5$ & 18.72 \\
\hline
\end{tabular}

\subsection{Optical setup}

Digital imaging analysis is performed by using a high-speed Complementary Metal Oxide Semiconductor (CMOS) color camera (Photron FASTCAM APX-RS) through a fixed $45^{\circ}$ mirror, which is placed inside the piston extension, provides a view of the combustion chamber from below. The maximum resolution $512 \times 512$ pixels can be achieved with the exposure $33.33 \mu$ s at frame rate 9000 fps. The color camera has a high sensitivity over a wide visible range, which enables recording the color information of spectral emissions during combustion. The electronic sensors of the camera record the spectrum of colors into three channels, one dominated by red, and the others by green and blue. The spectral response of the color camera, which describes the sensitivity of the photo-sensor to optical radiation of different wavelength, can be seen in Fig. 2. A Nikon lens (Nikon AF Nikkor 28$70 \mathrm{~mm} \mathrm{f} / 3.5$ ) is mounted at the front of the camera, which realizes a spatial resolution of 16.4 pixels $/ \mathrm{mm}$.

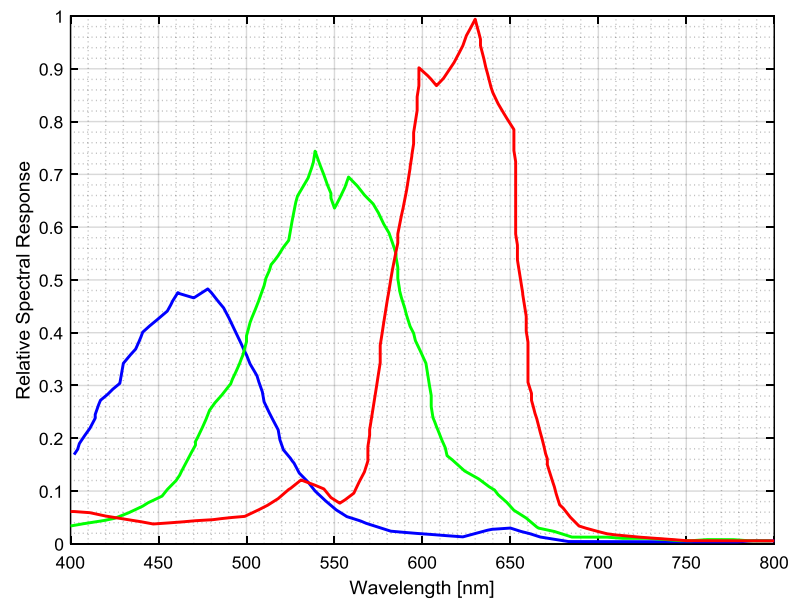

Fig.2 Relative spectral response curves of color-chrome camera

\subsection{Image quality assessment}

To assess the stablilities of the system and artificial errors, a metric method is adopted to compare the similaritieis of the raw images and reference images at the same crank angle. Here, the relevance index, $R_{i}$ is applied to to estimate the similarity degree of two images, the relevance index is given as:

$$
R_{i}=\sum_{i=1}^{n}\left(\frac{\operatorname{hist}\left(I_{\text {ref }}\right)}{\text { numel }\left(I_{\text {ref }}\right)}-\frac{\operatorname{hist}\left(I_{i}\right)}{\text { numel }\left(I_{i}\right)}\right)^{2}
$$

Where, $n$ is the snapshots of each cycle, hist $\left(I_{\text {ref }}\right)$ and hist $\left(I_{i}\right)$ are the histogram for the grayscale reference image and compared image, numel $\left(I_{\text {ref }}\right)$ and numel $\left(I_{i}\right)$ are the number of array elements for the grayscale reference image and compared image.

Fig.3 illustrates the similarity comparison of combustion images with aforementioned metric method. Since discernable differences can be observed between ImageNo.1 and ImageNo.2, the revelance index has a value $R_{i}=0.3885$. On the other hand, the relevance index of ImageNo. 2 and ImageNo. 3 is close to 
zero, $R_{i}=1.367 \mathrm{e}^{-4}$. It can be related to the similar sooty flame intensity and distribution. The results support that this metric method can be applied to measure the similarity degree of the images.

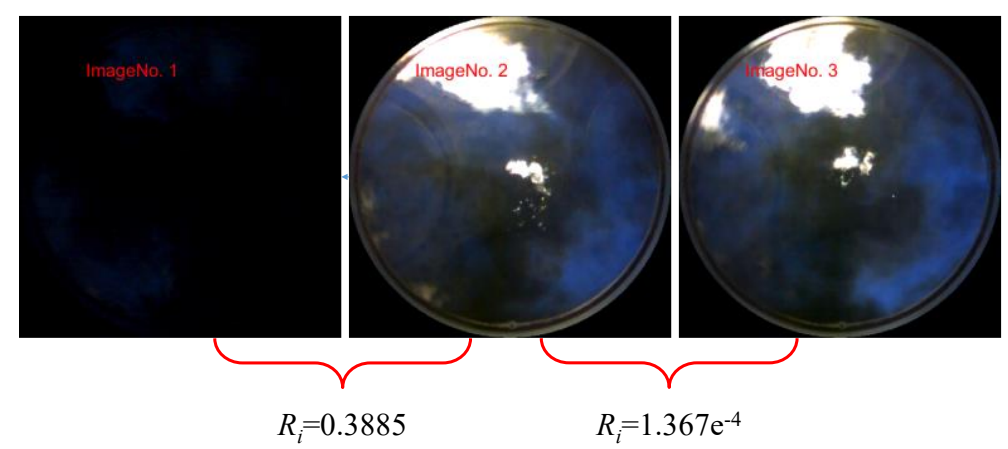

Fig.3 Similarity degree comparison between images based on metric method

Further comparisons are conducted beween reference cycles and sampled cycles. Fig. 4 demonstrates the comparison of 22 sampled cycles and two reference cycles. For each cycle, there are 75 images. It can be observed that the highest relevance indexes, $R_{i} \approx 0.2$, are taken place at the beginning of combustion (close to TDC) in cycle $12^{\text {th }}$ and cycle $14^{\text {th }}$. The relevance indixes of most cycles are lower than 0.1 , or even lower than 0.05 . This implies that there are minor differences among the reference cycles and sampled cycles. The results also support that the optical system is reliable.

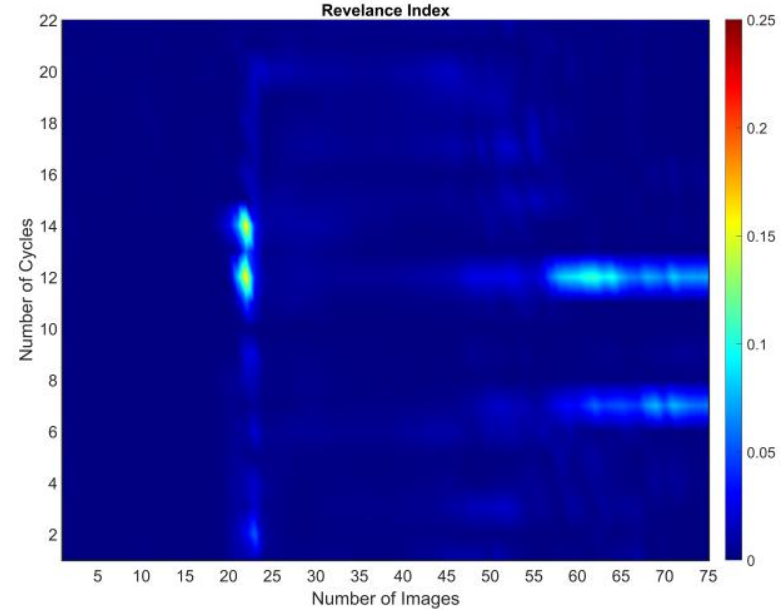

(a)

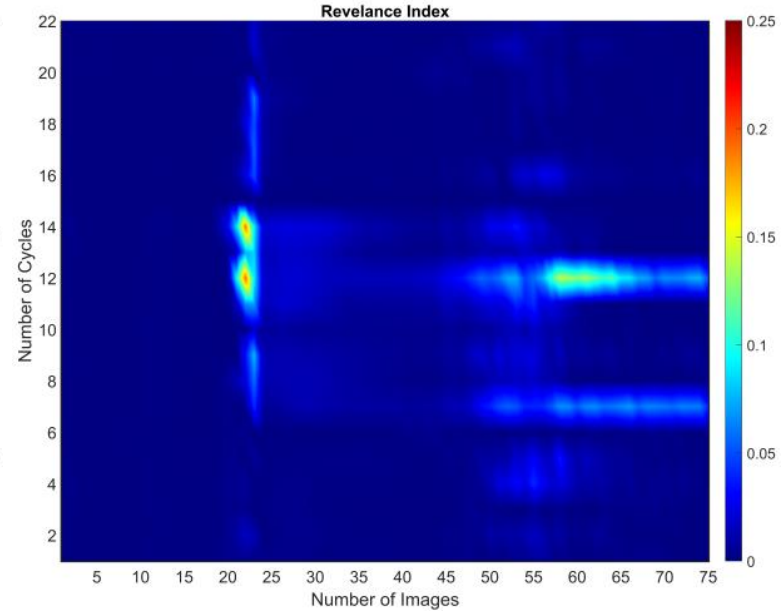

(b)

Fig.4 Similarity degree comparison between sample cycle images and reference images based on metric method, (a) Revelance index of comparison between sample cycles and reference cycle NO.1; (b) Revelance index of comparison between sample cycles and reference cycle NO.2

\section{Methodology}

\subsection{POD-based COV}

POD is a statistical method applied to extract dominant structures or patterns from a given data set [39]. Consider the case where the same phenomena are measured $n$ repetitions, each measurement $u_{k}(k=1$, $\ldots, K)$ is defined as snapshot, which contains a large number of real entries: $u_{k} \in R^{s}$. The $u_{k}$ can be assumed an image of flame luminosity obtained at the $k$-th repetition, and $s$ equal to the number of space positions $i \times j$, which is determined by the sensor resolution. A new matrix can be formed by reordering the snapshots $u_{k}$ as follows: 


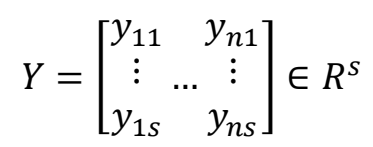

The goal is to find orthonormal basis vectors $\left\{\varphi_{1}, \ldots, \varphi_{s}\right\}$ that best approximates $Y$, for given $s<r$ $=\operatorname{rank}(Y)$. Mathematically, the situation can be described by mens of the optimization problem:

$$
\min _{\widehat{Y}}\left\{\|Y-\hat{Y}\|_{F}^{2}: \operatorname{rank}(\hat{Y})=s\right\}
$$

The solution to the optimization problem (2) is thus given by the orthogonal eigen functions $\varphi_{m}(x)$ :

$$
\varphi_{s}(x)=\sum_{k=1}^{K} \psi_{s k} u_{k}(x)
$$

where $\Psi=\psi_{1}, \Psi_{2}, \cdots, \Psi_{K}$ is obtained by solving the eigenvalue problem:

$$
C \Psi=\lambda \Psi
$$

In statistical applications, the covariance matrix $C$ can be replaced by its approximate:

$$
C=\frac{1}{K} Y^{T} Y
$$

Then, most information of $u_{k}$ can be approximated by a linear combination of the first $M$ modes:

$$
\hat{u}_{k}(x)=\sum_{m=1}^{M} c_{m k} \varphi_{m}(x)
$$

According to the COV derivation in $[35,36]$, the global POD-based COV at each crank angle (CA) can be given as:

$$
\operatorname{COV}=\sqrt{\sum_{m=1}^{M} \overline{c_{m}^{2}} / \sum_{m=1}^{M} \bar{c}_{m}^{2}-1}
$$

It is worth noting that Eq.(8) expresses the standard deviation of the scalar field in terms of lowdimensional POD coefficients $c_{m k}$, which include the intensity variance for every pixel. Consequently, the POD-based COV provides contributions in reducing computations and containing spatial luminosity information.

\subsection{Intensity-based COV}

The global integrated intensity of each snapshot image is calculated pixel-by-pixel. The intensity-based $\mathrm{COV}$ is defined as the standard deviation of the global integrated intensity at each CA. The global integrated intensity is given as:

$$
\operatorname{Int}_{k, t}=\sum_{i} \sum_{j} I_{i, j}
$$

where $I_{i, j}$ is the flame intensity at pixel position $(i, j)$, and $I n t_{k, t}$ is the kth snapshot at crank angle $t$.

The standard deviation of global integrated intensity at each CA is calculated as follow:

$$
\operatorname{ICOV}_{k, t}=\sqrt{\frac{\sum_{k=1}^{K}\left(I n t_{k, t}-\overline{I n t}_{k, t}\right)^{2}}{K-1}}
$$

where $\overline{\operatorname{Int}}_{k, t}$ is the averaged global integrated intensity at crank angle $t$.

\subsection{Pressure-based COV}

The cyclic variation in combustion results in cyclic variation in pressure. The pressure-based COV is defined as the standard deviation of cylinder pressure value as a function with crank angle $t$. The standard deviation of pressure at each CA is given as: 


$$
\operatorname{PCOV}_{k, t}=\sqrt{\frac{\sum_{k=1}^{K}\left(P_{k, t}-\bar{P}_{k, t}\right)^{2}}{K-1}}
$$

where $\bar{P}_{k, t}$ is the average pressure at crank angle $t$.

\section{Analysis procedure}

\subsection{Analysis of POD-based COV}

To gain more insight into the CCVs in dual-fuel combustion, 22 repetitions of images for each CA were captured for POD analyzing. Some original images at different CAs are shown in Fig.5. The initial blue color regions near the periphery of the wall can be observed at 3.7 CAD ATDC. This blue region is related to the spectrum of premixed flame, which shows blue color due to the emission of excited radicals (especially $\mathrm{CH}^{*}$ and $\mathrm{C}_{2} *$ band emission.) emitting most of wavelength below $565 \mathrm{~nm}$ in blue and green regions of the visible spectrum [40]. The blue regions can be assumed to be the lowtemeprature reaction zone. The bright sooty flame can be obseved at 13.0 CAD ATDC located at the pilot spray cloud zone. This sooty flame is produced by means of incandescence of soot particles in the rich diesel combustion zone [41]. It is worth noting that the pilot diesel is injected by two asymmetric holes, with very short injection duration. Additionally, the hole-to-hole and shot-to-shot variations lead to the asymmetry of the flame propagation. As a consequences, a sooty flame with high intensity can be observed near the exhaust valve, the other less sooty flame randomly appeared near the intake valve. The major variation at this moment is caused by the luminous intensity and spatial distribution of the sooty flame. The luminous intensity of the sooty flame gradually decreases due to the depletion of the pilot fuel at 22.4 CAD ATDC. The bright spots near the pilot injector still produce high luminous intensity. These bright spots are related to the injector dribbling creating locally fuel rich zones leading to soot formation [42]. The blue color still dominates in the combustion chamber, and the fluctuation in the luminosity fields starts to increase because in the non-simultaneous extinguishing rate of the sooty flame. The further decrease of the luminous intensity can be observed at 31.7 CAD ATDC due to the depletion of both diesel and CH4. It is worth noting that there is marginal variation in global luminous intensity; however, there is significant variation in the spatial sooty flame. This potentially indicates that the ignition characteristics (e.g. ignition delay and location) of the pilot fuel play a crucial role in dual-fuel CCVs.

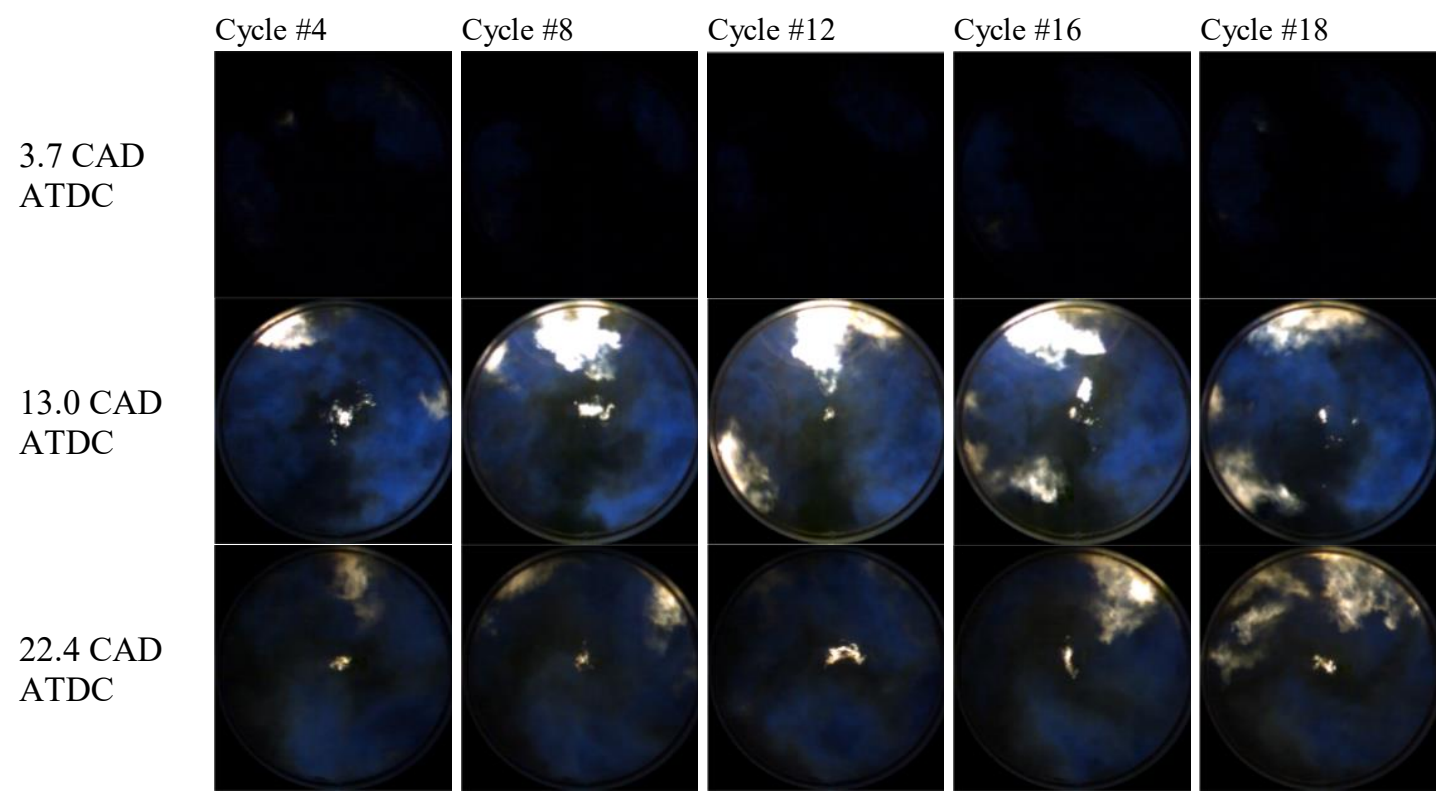



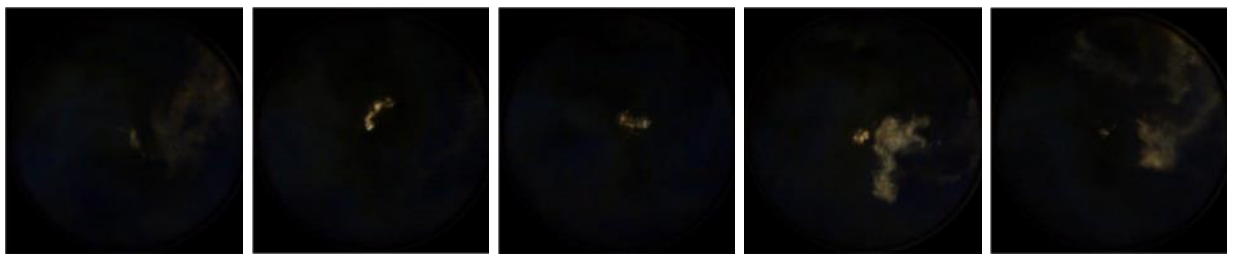

Fig.5 Typical images for five combustion cycles at four crank angles.

The POD modes are the optimal decomposition for the light emission during the combustion process and capture large-scale structures or a large-scale behavior of the flame luminosity. Fig.6 demonstrates six POD modes, computed over 22 cycles at 13 CAD ATDC. The first few modes contain most information of the average structure in the luminosity field. This corresponds to the total kinetic energy contained within the first few POD modes. Higher order modes contain the fluctuation information, which can be implemented to derive the coherent and incoherent parts in the luminosity field $[35,36]$.
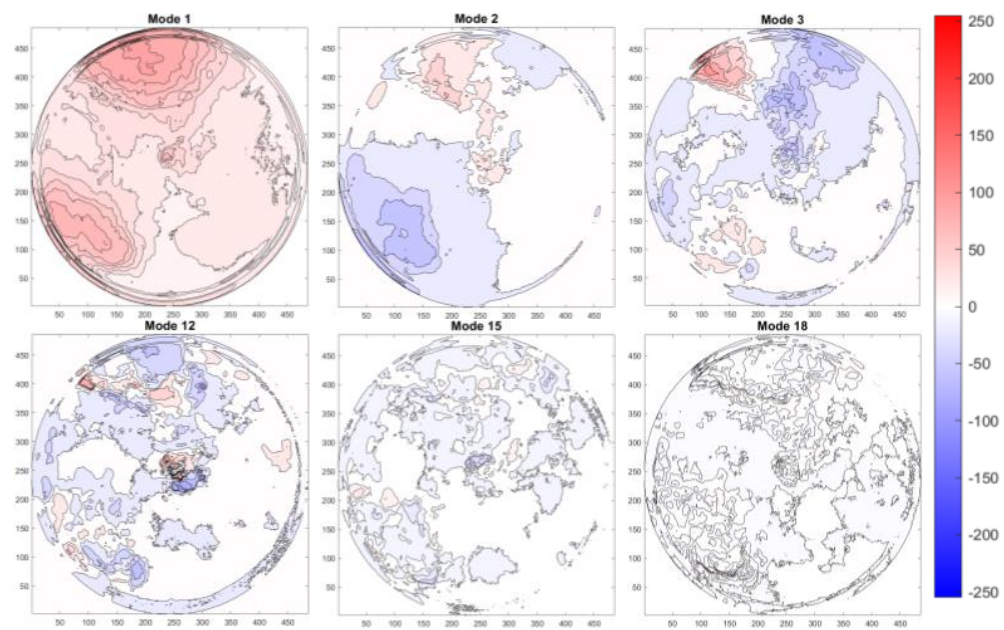

Fig.6 Leading (top) and some higher order POD modes (bottom) at $13 \mathrm{CAD}$

POD is applied to discriminate coherent and incoherent parts from the luminosity fields and to visualize the relevant morphologies. The idea is that the fluctuation of each cycle can be derived from the subtraction between individual and average images. The coherent and incoherent information can be extracted from this fluctuation based on POD. According to the method described in $[11,23,35,36]$, the fluctuation can be decomposed into non-Gaussian (coherent) and Gaussian (incoherent) components based on Karhunen-Loève theorem [43]. Consequently, the coherent and incoherent parts can be extracted from the fluctuation by computing relevant statistical properties of each $c_{i}^{\prime}$, termed as skewness $\left(\gamma_{1}\right)$ and kurtosis $\left(\beta_{2}\right)$ :

$$
\gamma_{1}=\frac{\overline{\left(c_{l}^{\prime}\right)^{3}}}{\sigma_{i}^{3}} ; \beta_{2}=\frac{\overline{\left(c_{l}^{\prime}\right)^{4}}}{\sigma_{i}^{4}}
$$

where $\sigma_{i}$ is the standard deviation of $c_{i}^{\prime}$. When reconstructing the fluctuation based on POD, a Gaussian coefficient $S$ will existe with $0 \leq S \leq M$, and can be implemented to separate the fluctuation into two parts. The first $S$ modes represent the coherent part and the remaining $M-S$ modes relate to the incoherent parts, which are given as:

$$
u^{\prime}=u_{c o h}^{\prime}+u_{\text {incoh }}^{\prime}=\sum_{i=0}^{S} c_{i, \text { coh }}^{\prime} \varphi_{i}+\sum_{i=S+1}^{M} c_{i, \text { incoh }}^{\prime} \varphi_{i}
$$

Fig.7 illustrates the decomposition of the first snapshot of the in-cylinder luminosity field at $13 \mathrm{CAD}$ ATDC. The gray-scaled image $u_{1}$ is converted from the original RGB image, and the mean field $\bar{u}$ is the average of all 22 repetitions at 13 CAD ATDC. The separation of coherent and incoherent parts is derived from the magnitude of the eigenvalues. The fluctuation information can be observed in the images below; the incoherent part has a distinct "random" spatial distribution, which highlights the 
unrepeatable phenomenon; in contrast, the coherent part has a more organized structure, which represents a repeatable phenomenon.

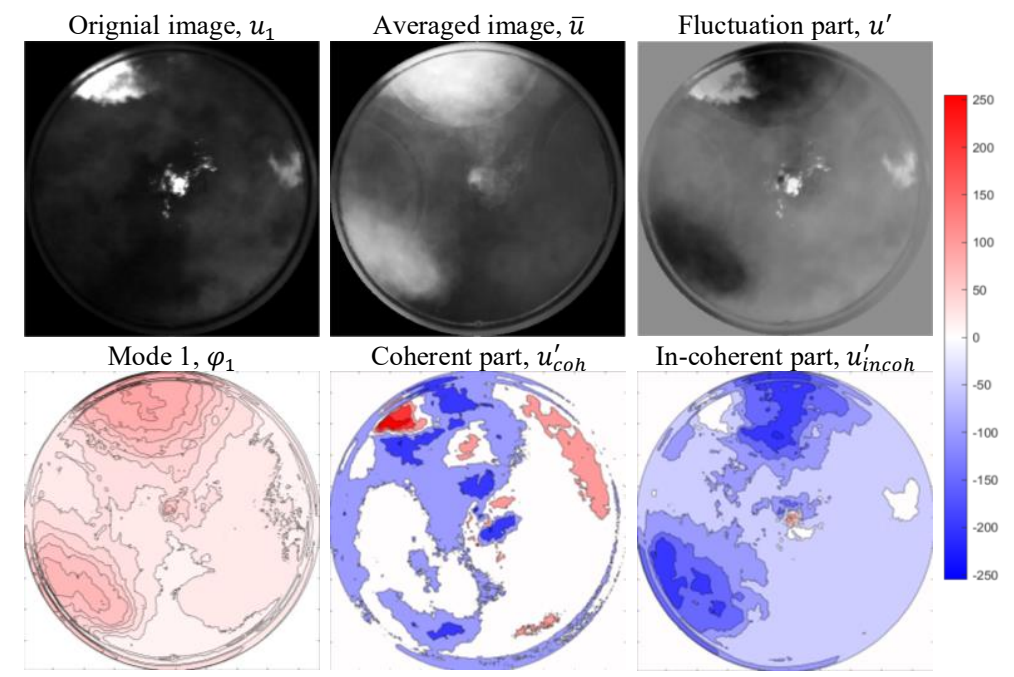

Fig.7 Gray-scaled, average and fluctuation images (top) and decomposition parts of the first POD mode, coherent and incoherent (bottom) at 13 CAD ATDC

The number of samples play a crucial role in POD reconstruction. In our case, around 22 continous fired cycles can be captured for each shot. Therefore, the sample size of usability evaluation is essential to attain a desirable level of precision. Fig. 8 shows the POD-based COVs with different sample sizes. The results show that there is minor differences with increasing the sample size. Considering the balance between the level of precision and image post-processing time, we fianally select one shot with 22 cycles as POD-based sample.

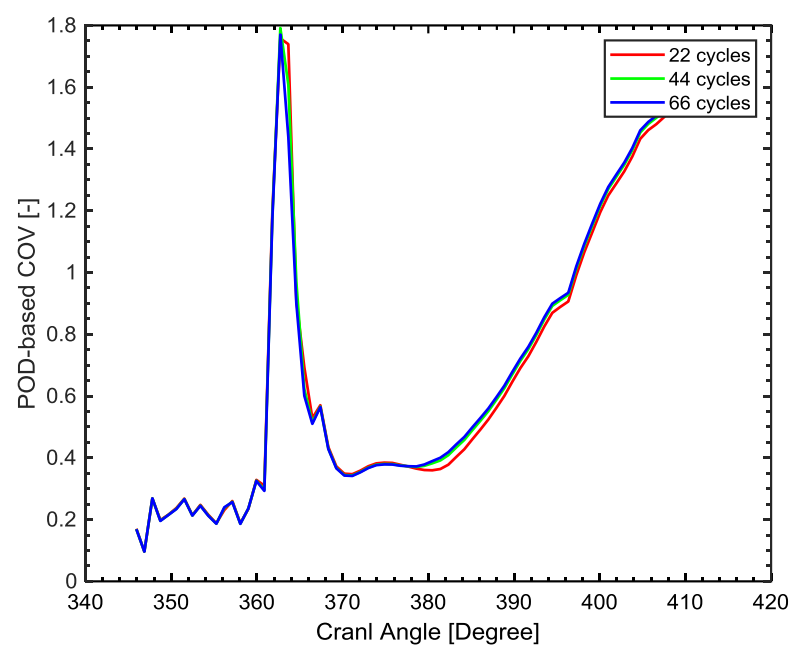

Fig.8 Sample size evaluation with POD-based COVs

\subsection{Analysis of Intensity-based COV}

The integrated intensity of each frame can provide a quantitative description for the observations in images. Fig.9 (a) shows the global integrated intensity and intensity in RGB channels as functions of crank angle. The color intensity analysis based on the intensity separated from RGB channels provide a possibility to visualize the spectral sensitivity. The integrated intensity of green channel displays the highest sensitivity at the beginning of combustion, while blue channel exhibits the marginal differences in integrated luminous intensity. The color-intensity-based COV defined as the standard deviation of integrated intensity based on RGB channels, and the global integrated intensity is derived from grayscaled image, which can be computed through the intensity of light at each pixel according to a 
particular weighted factor. The global-intensity-based COV and color-intensity-based COV are shown in Fig.9 (b). The interpretation of the differences of the color-intensity-based COV are related to the spectral response of the color camera with different wavelengths of the radical emissions [46]. The color-intensity-based COV shows that the peak COV of the green channel is at $361.8 \mathrm{CAD}$, followed by the blue channel at 362.7 CAD and the red channel at 364.6 CAD. The green channel displays the highest sensitivity in luminous intensity variation. This can be related to the relative spectral response of the color camera in RGB channels and emission spectrum of radicals during combustion. On the one hand, Fig. 2 shows the relative spectral response of the Photron FASTCAM APX-RS. It can be observed that relative spectral response of green channel $(450-650 \mathrm{~nm})$ displays some overlap between the bands in the region of blue-green $(450-550 \mathrm{~nm})$ and green-red $(550-650 \mathrm{~nm})$. That means the green channel contains some blue and red information. Therefore, the global-intensity-based COV is more sensitive to the green channel. On the other hand, the production and consumption of the spectrometry of $\mathrm{OH}^{*}$ (308nm), CH* (430nm), C2* (436-563nm), CO2* (340-650nm), CH2O* (330 nm) during dual-fuel combustion are located in green region and all these radicals have high reactivity during combustion, which contributes to an increase in the COV in the green channel. On the contrary, the blue channel shows the lowest COV due to lower spectral response in the blue channel and lower reactivity of the radicals with shorter wavelength (below $500 \mathrm{~nm}$ ) during low temperature combustion. The red channel shows the latest appearance of luminous signal due to the soot dominate flame with the longer wavelength. It is worth noting that the global-intensity-based COV is less sensitive to the red and blue channels, but more sensitive to the green channel, which can be observed from Fig.9 (b).

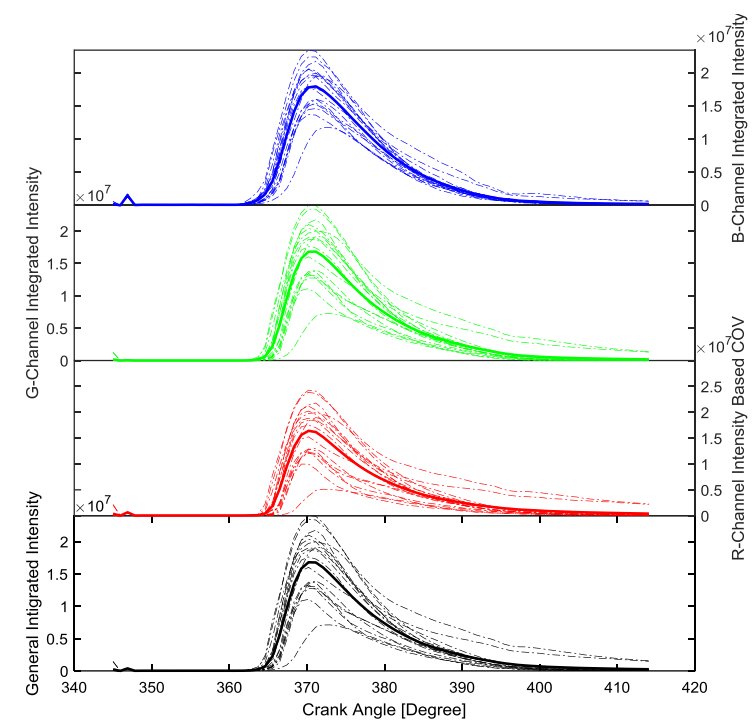

(a)

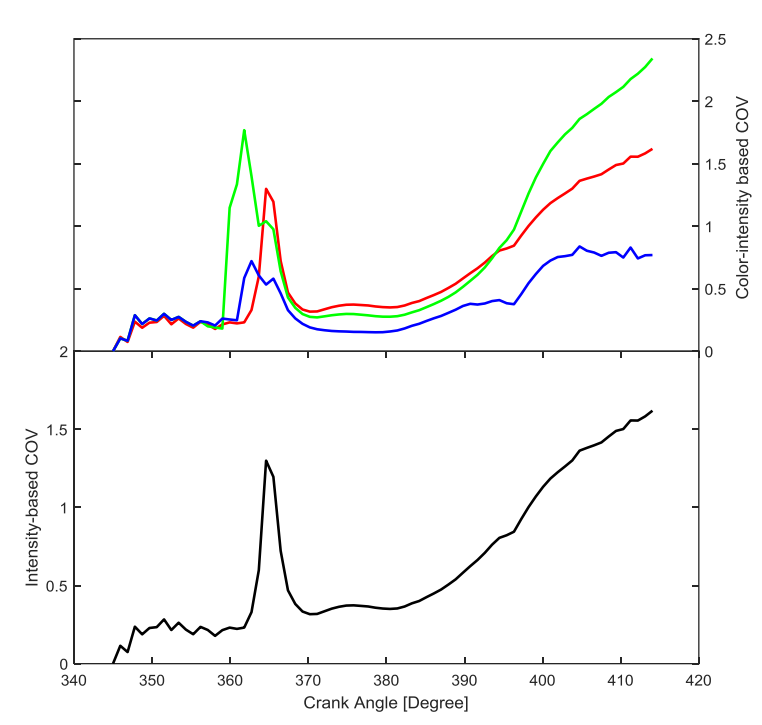

(b)

Fig.9 (a) Global integrated intensity and intensity in RGB channels (left), (b) Color-intensity-based COV (Top) and Global-intensity-based COV (Bottom)

\subsection{Analysis of Pressure-based COV}

Fig. 10 shows the measured cylinder pressure (bottom), HRR (middle) and the standard deviation of the cylinder pressure, namely pressure-based COV (top), with $\lambda_{\mathrm{CH}^{4}}=2.0, t_{\text {pilot }}=0.8 \mathrm{~ms}$ and $T_{\text {air }}=298 \mathrm{~K}$. It is worth noting that the optical engine was operated in skip fire mode at 1400rpm, and 22 continuous fired cycles were selected for cyclic variation analysis. The dash lines illustrate the individual cylinder pressure and HRR for each cycle; the average cylinder pressure and HRR are plotted with solid lines.

An evidence of two-stage combustion can be observed from the HRR curves. The first peak of average HRR occurs at 6.0 CAD ATDC, which corresponds to the combustion of $\mathrm{CH} 4$ in the premixed pilotregion. The second peak can be observed when the flame propagates through the $\mathrm{CH} 4$-air mixture. It 
can be observed that the highest variation occurs at the peak of averaged HRR, which indicates that the pressure-based $\mathrm{COV}$ is determined by the thermodynamic process during combustion. The second peak of averaged HRR also leads to the increase in the pressure fluctuation, which can be observed in pressure-based COV.

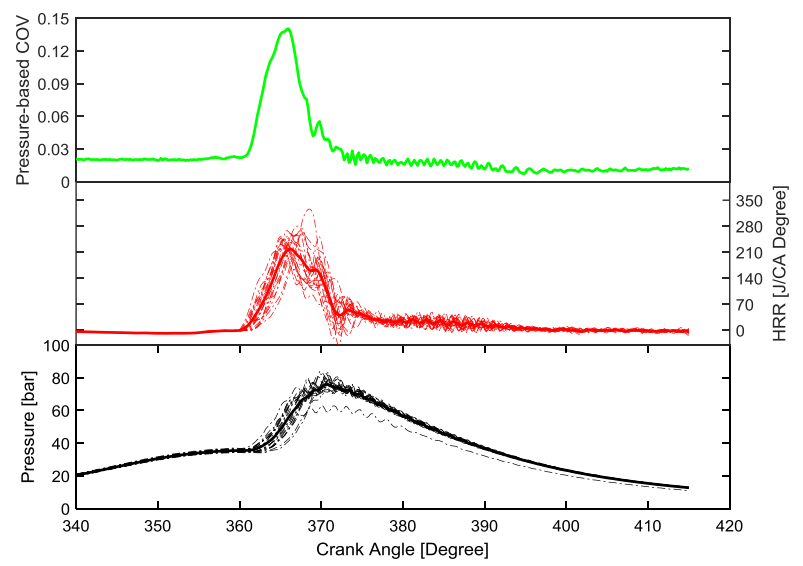

Fig.10 Pressure-based COV (top); HRR (middle); cylinder pressure (bottom) at CH4 lambda 2.0, pilot duration $0.8 \mathrm{~ms}$ and charge air temperature $298 \mathrm{~K}$

\subsection{Temperal-Spatial Features of POD-based COV}

To estimate the fluacuation level of the dual-fuel combustion, the incoherent part of POD-based fluctuation is reconstructed to different fluctuation levels, and the scale typically range from -5 to 5 based on the intensity distribution of incoherent part. As shown in Fig. 11(a), a four dimensional plot of the incoherent parts of the POD at different crank angles is adopted to exhibite the temporal-spatial features of the POD-based COV. To clarify the fluacuation in spatial, two planar plots cross the center of the cylinder are shown the fluactuation level in different sections, which can be seen in Fig11(b) and (c). Accoding to the previous analysis, the positive fluactuation, namely, the intensity higher than the averagy intensity which is shown with red. Conversely, shown with blue.

Fig. 11 demostrates the POD-based fluactuation at condition of $\lambda_{\mathrm{CH} 4}=2.0, t_{\text {pilot }}=0.8 \mathrm{~ms}$ and $T_{\text {air }}=298 \mathrm{~K}$. It can be observed that the sooty flame of the pilot diesel has positive effects on the POD-based fluctuation, because the intensity of sooty flame is higher than the average intensity. Coversly, premixed flame of the $\mathrm{CH} 4$ has negative effects on the fluctuation due to the lower intensity. The location of the positive fluactuation is rotated with time, because of the swirl in the cylinder. The fluctuation of the premixed combustion can be observed at 8 CAD BTDC, which is consisted with the previous analysis. With cylinder temperature increasing, the sooty flame fluctuation can be observed at 2 CAD BTDC. The appearance of the sooty flame loacated near the nozzle with the coordinate in spatial is $[\mathrm{X}, \mathrm{Y}]=[243$ $243]$ in pixels. In the Y palne, the positive fluactuations are located at $0-120,200-250$ and 380-486 in pixels, which can be attributed to the flames from two nozzles and the dribbling. In this case, the main combustion accurs during 8 CAD BTDC and 20 CAD ATDC. After the main combustion, the negative fluctuation still can be observed until $40 \mathrm{CAD}$ ATDC. According to the temporal-spatial features of POD-based fluactuation, it can be observed the effects of pilot fuel (diesel)and main fuel (CH4) on cycle-to-cycle variations in dual-fuel combustion. It is worth to note that the criteria of the fluactuation is based on the cycles of the each case. Therefore, it can not be used for the comparison of different cases. 

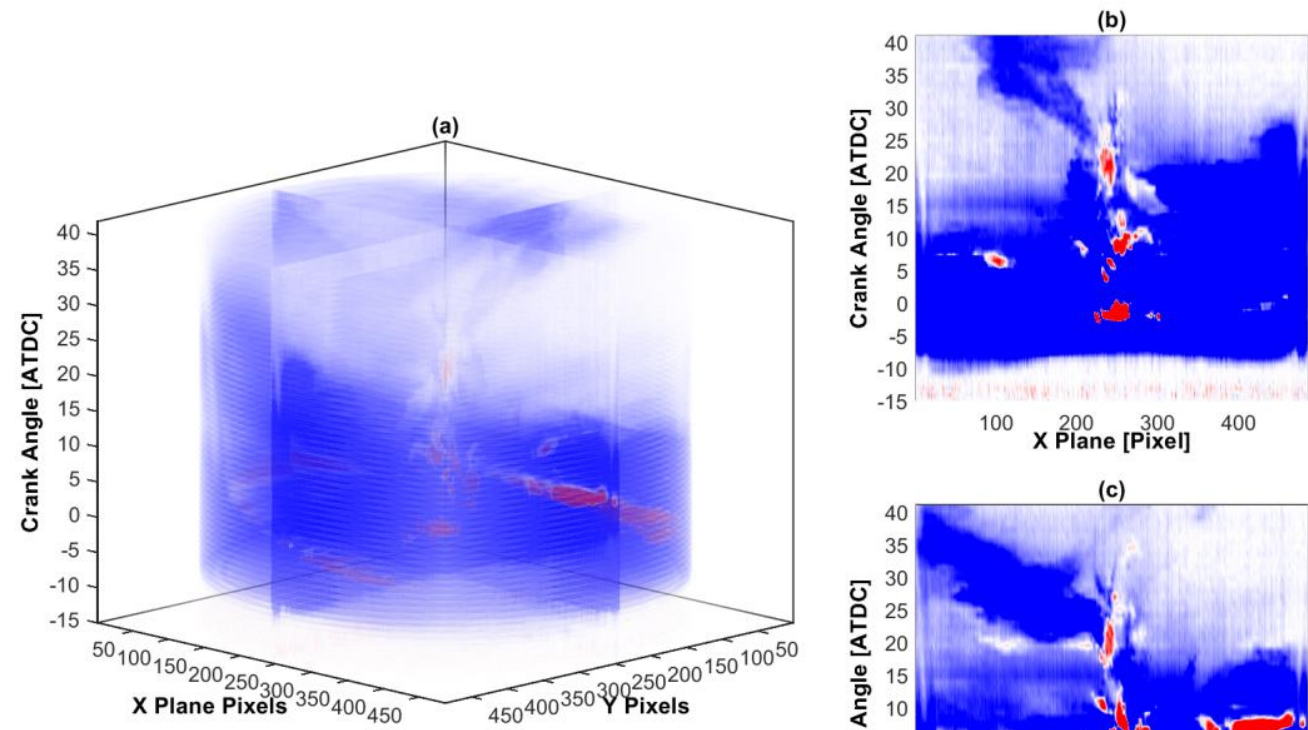

(c)
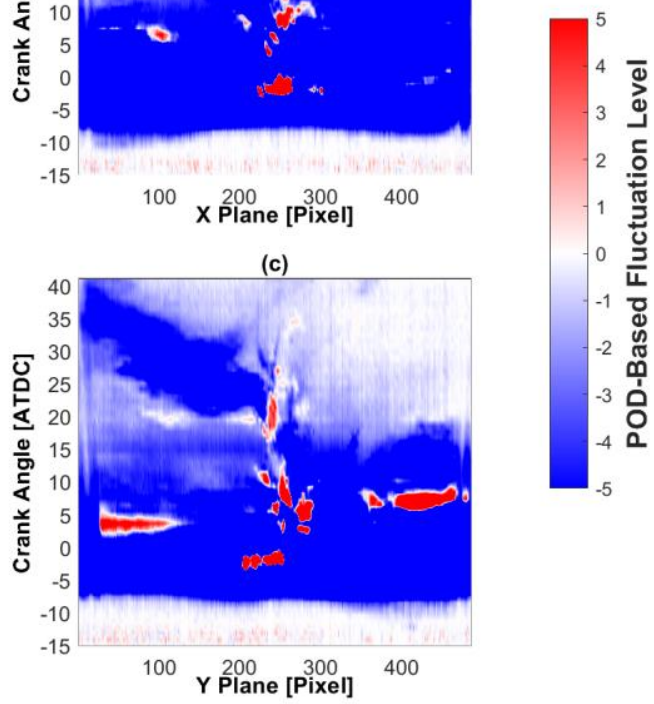

Fig.11 Temporal-spatial features of POD-based fluctuations. (a) 4-D plot; (b) X-plane; (c) Y-plane

\section{Results and discussion}

To gain an insight into the effects of operating parameters on CCVs, the Results section presents observations from the measurements concerning the characteristics of dual-fuel combustion and the resulting CCVs, with variable $\lambda_{\mathrm{CH} 4}, t_{\text {pilot }}$ and $T_{\text {air. }}$. For each variable, a systematic analysis of CCV based on global and color intensity, POD and cylinder pressure are applied to assess the source of the variations.

\subsection{Effect of CH4 lambda on the CCV}

The effect of $\mathrm{CH} 4$ lambda on the $\mathrm{CCV}$ of dual-fuel combustion is examined by acquiring crank angle resolved images and cylinder pressures. $\lambda_{\mathrm{CH} 4}$ is varied from 1.6 to 2.0. Charge air temperature and pressure are kept at $298 \mathrm{~K}$ and 1.3 bar in all cases with an aim to vary $\lambda_{\mathrm{CH}}$ by keeping the air mass flow at $50.5 \mathrm{~kg} / \mathrm{h}$ while only varying the methane mass flow rates.

Fig. 12(a) depicts the global intensity (bottom) and intensity-based COV (top) with different $\lambda_{\mathrm{CH} 4}$. The global intensity displays a monotonic increase with the decrease of $\lambda_{\mathrm{CH} 4}$. The addition of $\mathrm{CH} 4$ has an increasingly significant effect on low and high temperature reaction in diesel-CH4-air mixture, which results in longer ignition delay time (IDT) and more luminous soot emission. The intensity-based COV under ultra-lean conditions $\left(\lambda_{\mathrm{CH} 4}=2.0\right)$ shows the earliest appearance of variation in luminosity field, followed by $\lambda_{\mathrm{CH} 4}=1.8$ and $\lambda_{\mathrm{CH} 4}=1.6$. The prolonged IDT indicates that the addition of $\mathrm{CH} 4$ has an inhibiting effect on the auto-ignition process [43]. The ultra-lean conditions $\left(\lambda_{\mathrm{CH} 4}=2.0\right)$ also exhibits higher variation. This is because under these ultra-lean conditions, the flame kernels grow slowly, the flame quenching and turbulent kinetic energy decay greatly influence the stability of the combustion. The richer $\mathrm{CH} 4$-air mixture condition $\left(\lambda_{\mathrm{CH} 4}=1.6\right)$ shows the latest and lowest intensity-based $\mathrm{COV}$, which is related to prolonged IDT and continuous stable flame propagation. The similar peak intensitybased COV can be observed between $\lambda_{\mathrm{CH} 4}=2.0$ and $\lambda_{\mathrm{CH} 4}=1.8$; however, the appearance of intensitybased $\mathrm{COV}$ at $\lambda_{\mathrm{CH} 4}=1.8$ suggests a $1 \mathrm{CAD}$ delay. 
The color-intensity (bottom) and color-intensity based COV (top) are shown in Fig.12(b). The blue channel detects the signal initially, followed by greed and red. This sequence of signal appearance is related to the flame spectrum and temperature. It has been commonly proven that there is a blue glow that can be observed at the beginning of the ignition because of the radical emissions at low temperature reaction. With the increase in the amount of $\mathrm{CH} 4$ under high temperature conditions, it transits to normal yellow flame [45]. The blue channel shows the highest intensity in all the cases, which results in dominant $\mathrm{CH} 4$ flame in the cylinder. This is because the $\mathrm{CH} 4$-diesel-air mixture burns under lean conditions, less soot radiating black body is produced due to more complete combustion and the reaction creates enough energy to excite and ionize gas molecules in the flame (e.g.: $\mathrm{CH}^{*}, \mathrm{C} 2^{*}$, etc.) [42]. The green channel exhibits the earliest and highest color-intensity-based COV, which implies that the emission of excited radicals emit most of their light well below $600 \mathrm{~nm}$, and there is significant fluctuation of these excited radicals emission at the beginning of ignition. The blue channel has less sensitivity to the emission of excited radicals due to lower spectral response. The inhibition effect of $\mathrm{CH} 4$ on the chemical reaction in diesel-lean mixture can be observed in the color-intensity-based COV. It can be seen that the appearance of COVs are retarded with the decrease of $\lambda_{\mathrm{CH} 4}$. With further decrease the $\lambda_{\mathrm{CH} 4}$, the intensity fluctuation in all channels are retarded and decreased. The interpretation is related to the prolonged IDT and stable combustion in the relative richer $\mathrm{CH} 4$ condition.

Fig.12(c) demonstrates the cylinder pressure (bottom) and HRR (top) with crank angle. The inhibition effect of additing CH4 also can be observed in HRR. The peak of the HRR increases with the addition of $\mathrm{CH} 4$, and the single-stage combustion gradually separates to two-stage combustion. This is predominantly due to the flammability of the $\mathrm{CH} 4$-air mixture. There is a low flame speed and unstable combustion under the ultra-lean $\mathrm{CH} 4$ conditions, which leads to lower heat release. On the contrary, the richer $\mathrm{CH} 4$-air mixture benefits the flame propagation of the pilot diesel cloud. Meanwhile, the prolonged IDT also advances the diesel-CH4-air mixing process.

The systematical analysis of the effect of $\lambda_{\mathrm{CH} 4}$ on CCVs based on different methods is shown in Fig.12(d). Similar trends between POD-based and intensity-based COV can be observed; however, there are significant differences of COVs in luminosity field and cylinder pressure. The highest variation of POD-based and intensity-based COV occurs at 363.7 CAD with $\lambda_{\mathrm{CH} 4}=2.0$, while this value is 368.2 CAD for the pressure-based COV. The peaks of POD-based and intensity-based COV at $\lambda_{\mathrm{CH} 4}$ $=2.0$ and $\lambda_{\mathrm{CH} 4}=1.8$ are similar; however, there is a significant difference between pressure-based COV and POD-based COV. This differences could potentially be attributed to the different transmission path of the emission of excited radicals and pressure wave in the cylinder. The luminosity field provides a popular and direct way to visualize the intensity of the chemical reaction, and cylinder pressure can yield some information about thermodynamics. It is interesting to note that the inhibition effect of $\mathrm{CH} 4$ on ignition delay can be observed in pressure-based COV, which display a later rising of pressure-based $\mathrm{COV}$ with decreasing the $\lambda_{\mathrm{CH} 4}$. This phenomenon is consistent with the conclusion in luminosity field. According to the POD-based and intensity-based COV, richer $\mathrm{CH} 4$-air mixture conditions enhance the combustion stability. However, the pressure-based COVs of $\lambda_{\mathrm{CH} 4}=1.6$ and $\lambda_{\mathrm{CH} 4}=1.8$ exhibited a paradox phenonmenon. It can be attributed to the turbulent flame propagation in the remaining unburned diluted methane-air mixture, which leads to instabilities in thermodynamics. 


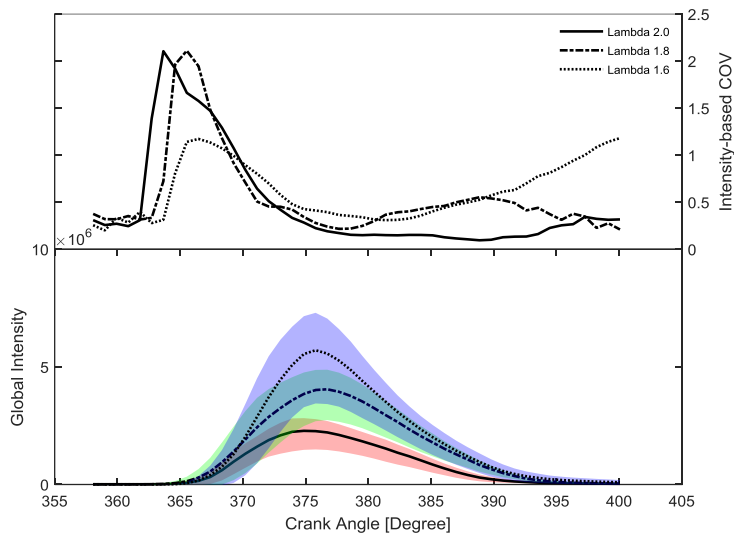

(a)

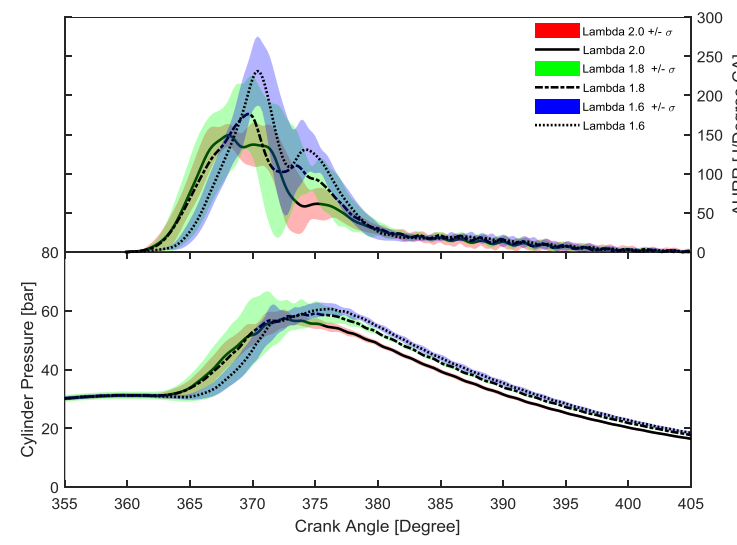

(c)

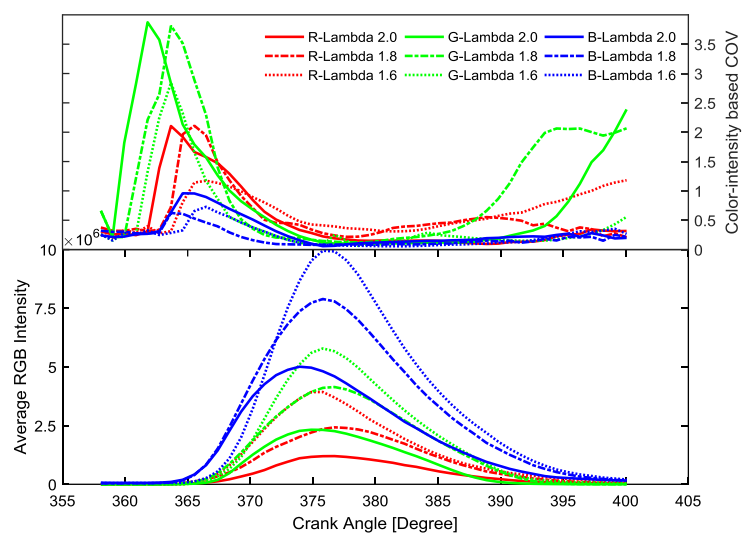

(b)

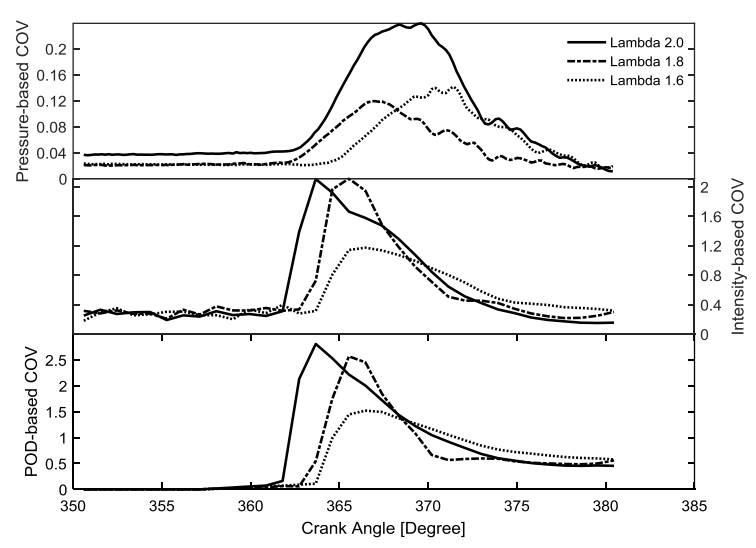

(d)

Fig.12 Effect of $\lambda_{\mathrm{CH} 4}$ on CCVs. (a) global intensity and intensity-based COV; (b) color intensity and color-intensity based COV (R-, G-, B- represent the intensity or COV in red, green and blue channel, respctively); (c) cylinder pressure and HRR; (d) comparison of the COVs based on POD, global intensity and cylinder pressure

Fig.13-15 demonstrate the temeporal-spatial features of POD-based fluactuation level with different $\lambda_{\text {сH4 }}$. According to the principle of POD, the coherent part includes all fluctuations with a somewhat structured feature over the cycles, while the incoherent part should include all fluctuations for which no pattern can be identified over cycles [40]. Here, the incoherent part of POD-based intensity is adopted to estimate the fluacutaction level. The false color in incoherent part shows the fluctuation of the luminous intensity value, "red"represents the local luminous intensity of $u_{1}$ higher than $\bar{u}$, and conversely, "blue" represents the local luminous intensity of $u_{1}$ lower than $\bar{u}$.

For $\lambda_{\mathrm{CH} 4}=2.0$, the combustion in cylinder is slow and weak, the intensity of natural luminosity is low due to the lean burn combustion. The premixed flame is dominant, which shows more deep blue in the cylinder. The main fluactuation of sooty flame can be observed after 5 CAD ATDC, and the fluctuation level is lower than 4. After 15 CAD ATDC, a higher fluctuation level can be observed close to the center (with coordinate [243 243] in pixels) due to the dribbling. In the case of $\lambda_{\mathrm{CH}_{4}}=1.8$, the temporalspatial features of the POD-based fluctuation is more extensive, while the absolute luminous intensity still exhibites low intensity. In this case, the sooty flame have more contributions on the positive fluctuation than previous due to more energy contains in this case. The temeprature is higher and more sooty flame can be observed. With the addition of the $\mathrm{CH} 4$ even more, the luminous intensity incylinder is further increased, and the luminous soot arround the diesel cloud is stronger, which can be observed in $\lambda_{\mathrm{CH}_{4}}=1$.6. It can be seen that higher positive fluctuations (red) are dominat in X-Plane and 
Yplane. It is interesting to note that the incoherent part is located in the luminous soot regions, which implies that luminous soot carries most of the flame shap information of "random" spatial distribution under richer conditions.
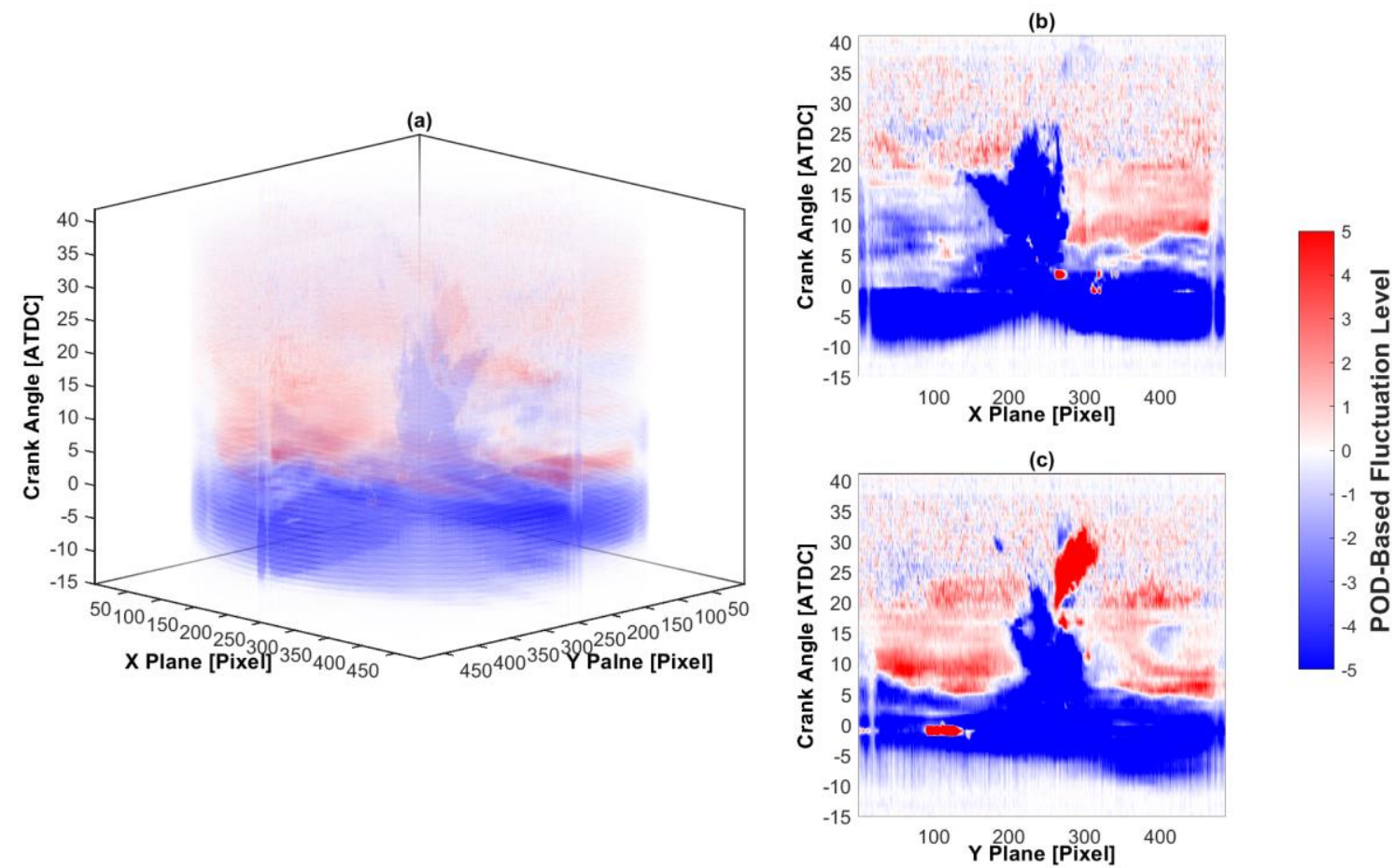

Fig.13 Temporal-spatial features of POD-based fluctuations. (a) 4-D plot; (b) X-plane; (c) Y-plane at condition of $\lambda_{\mathrm{CH} 4}=2.0, t_{\text {pilot }}=0.45 \mathrm{~ms}$ and $T_{\text {air }}=298 \mathrm{~K}$
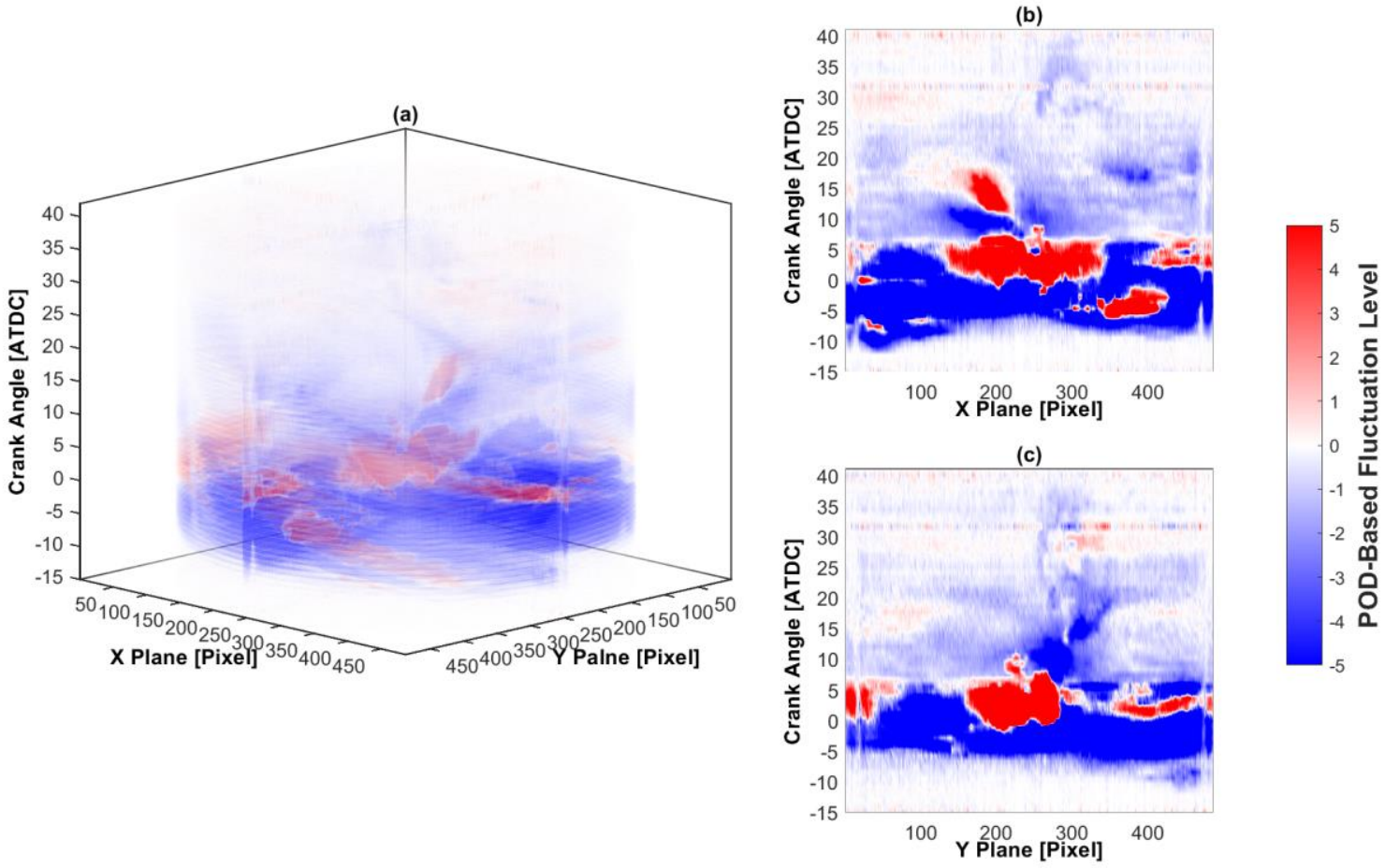
Fig.14 Temporal-spatial features of POD-based fluctuations. (a) 4-D plot; (b) X-plane; (c) Y-plane at condition of $\lambda_{\mathrm{CH} 4}=1.8, t_{\text {pilot }}=0.45 \mathrm{~ms}$ and $T_{\text {air }}=298 \mathrm{~K}$
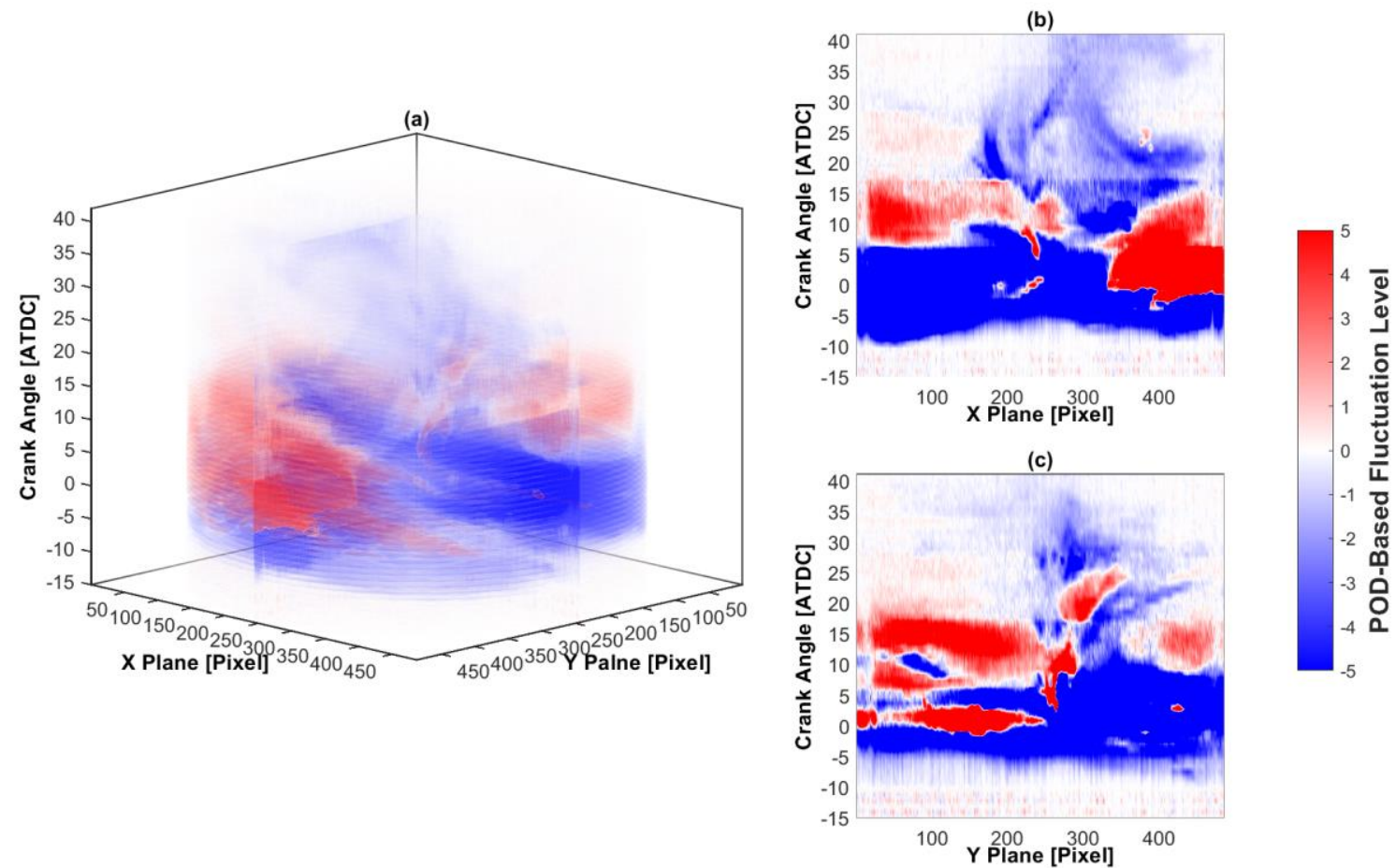

Fig.15 Temporal-spatial features of POD-based fluctuations. (a) 4-D plot; (b) X-plane; (c) Y-plane at condition of $\lambda_{\mathrm{CH} 4}=1.6, t_{\text {pilot }}=0.45 \mathrm{~ms}$ and $T_{\text {air }}=298 \mathrm{~K}$

\subsection{Effect of pilot fuel duration on the $\mathrm{CCV}$}

Fig.16 (a) illustrates the global intensity (bottom) and intensity-based COV (top) with different pilot fuel durations $\left(t_{\text {pilot }}\right)$. The global intensity displays a monotonic increase with the increase of $t_{\text {pilot. }} t_{\text {pilot }}=$ $0.7 \mathrm{~ms}$ shows the lowest peak and latest increase in the intensity-based COV, while $t_{\text {pilot }}=0.45$ and $0.60 \mathrm{~ms}$ have a similar peak of the intensity-based COV, and $t_{\text {pilot }}=0.6 \mathrm{~ms}$ exhibits the earliest increase in the intensity-based COV. It is worth noting that the engine runs under ultra-lean conditions $\left(\lambda_{\mathrm{CH} 4}\right.$ $=2.0$ ), which implies there is a low flame speed or fast extinction of the flame kernels. Thus, the amount of pilot fuel plays a crucial role in the stability of the dual-fuel combustion. As usual, larger pilot amounts provide a greater multitude of ignition centers with larger reaction zones, which act as a source of ignition energy for methane-air mixture [47]. Furthermore, with larger pilot amounts, the volume of premixed methane-air mixture entrained in the pilot fuel will also increase and thus, result in an increase in the burn fractions of the premixed mixture and a more successful flame propagation. Consequently, the high-intensity burn zones in regions of the vaporized pilot spray increases with the increase in the pilot fuel duration. The intensity-based COV shows that increasing the pilot fuel amount has the potential to reduce cyclic variations. This is potentially attributed to the addition of the high reactivity pilot diesel, which improves the stabilities of the ignition process [48].

Fig. 16(b). indicates the sensitivities of the RGB intensity with the different $t_{\text {pilot }}$. The signal of the blue channel exhibits the highest intensity and earliest appearance during combustion, followed by green and red. It is interesting to note that the addition of pilot fuel has a marginal effect on the appearance of green-intensity COV; however, it has a significant effect on the intensity of the cyclic variations. It can 
be observed that the peak of green-intensity COV is decreased with the addition of pilot fuel amounts. Similar trends can be found in blue and red channels. This implies that the addition of pilot fuel amounts under ultra-lean $\mathrm{CH} 4$ conditions is beneficial when creating a stable chemical reaction environment for the $\mathrm{CH} 4$-diesel-air mixture.

Fig. 16(c) depicts the cylinder pressure (bottom) and HRR (top) with crank angle. With the increase in the pilot fuel duration, more pilot energy is added into the system, which increases the peak cylinder pressure and HRR. The addition of pilot fuel amount improves the entrainment between CH4-air mixture and pilot fuel, and then promotes the premixed combustion of CH4-diesel-air mixture. Similar IDTs with different $t_{\text {pilot }}$ can be observed in the HRR curve, which indicates that there is a marginal effect of pilot fuel ratio on IDT.

The comparison of the effect of pilot fuel duration on CCVs based on different methods is illustrated in Fig.16(d). Similar trends of COVs based on POD, global intensity and pressure can be observed. It seems that pilot duration has a minor effect on the cyclic variations, especially at short pilot duration. There are similar peaks of COVs between $t_{\text {pilot }}=0.45$ and $0.60 \mathrm{~ms}$ based on luminosity field and cylinder pressure. The further addition of pilot fuel amounts has a significant effect on CCVs, which indicates that there is a dramatic drop with the COVs. It should be noted that the engine runs under ultra-lean conditions, the high reactive pilot fuel mixed with $\mathrm{CH} 4$-air mixture to create the diesel cloud, and then ignite and spread. It can be assumed that the CCVs are determined by the volume of the diesel cloud at the beginning of ignition. If the diesel cloud has a low proportion of the volume in the cylinder, it probably has less effects on the CCVs. The POD-based COV shows an evident retarded appearance of $\mathrm{CCVs}$ with increasing the $t_{\text {pilot }}$, which indicates the addition of high reactive pilot fuel has an inhibition effect on the cyclic variation at low-temperature ignition stage.

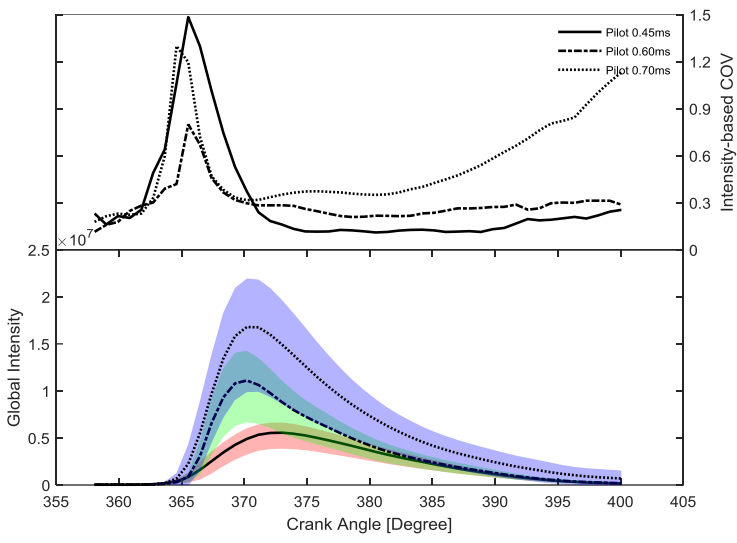

(a)

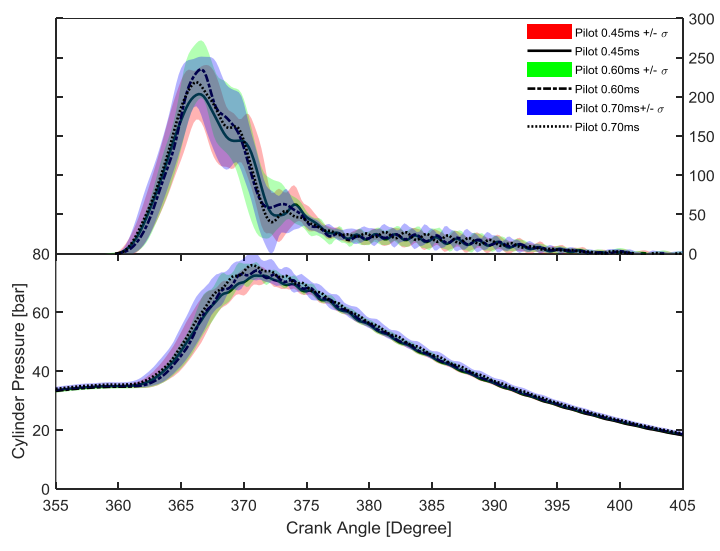

(c)

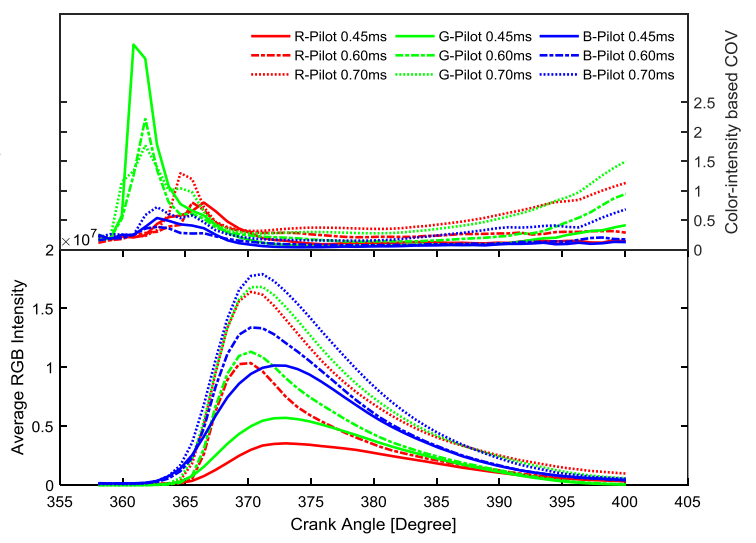

(b)

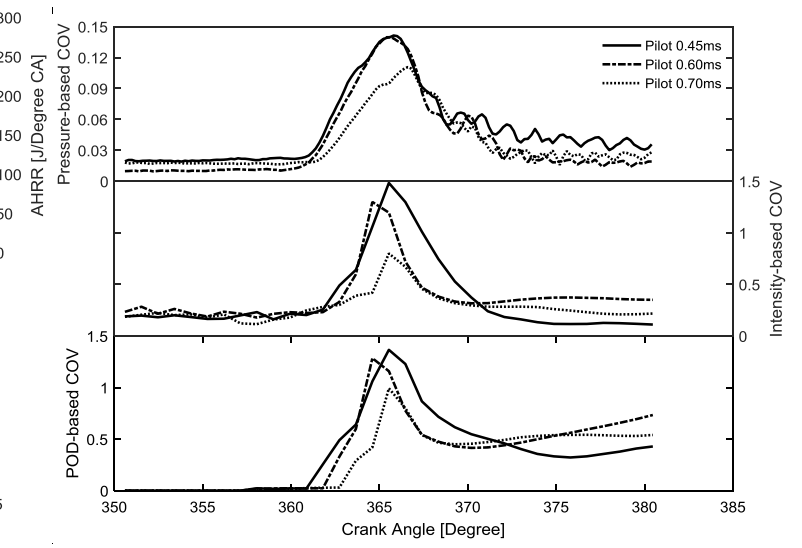

(d) 
Fig. 16 Effect of pilot fuel ratio on CCVs. (a) global intensity and intensity-based COV; (b) color intensity and color-intensity based COV (R-, G-, B- represent the intensity or COV in red, green and blue channel, respctively); (c) cylinder pressure and HRR; (d) comparison of the COVs based on POD, global intensity and cylinder pressure

Fig.17-19 illustrate the temeporal-spatial features of POD-based fluactuation level with different $t_{\text {pilot }}$. For $t_{\text {pilot }}=0.45 \mathrm{~ms}$, the "random" small pieces of fluctuation can be observed, the "red" can be observed near the nozzle to shows no pattern of the dribbling over cycles. In the case of $t_{\text {pilot }}=0.60 \mathrm{~ms}$, the spatial distibution of the incoherent part is more extensive, more fluactuation coused by sooty flame can be observed and the fluacutation level is higher than the case of $t_{\text {pilot }}=0.45 \mathrm{~ms}$. This can be attributed to the diffusion flame of the pilot diesel. More diesel amount greatly increase the level of luminous intensity, and generate more sooty flame. Therefore, the sooty flame has more contribution on the fluactuation. It is worth to note that the fluctuation level of premixed flame is lower than the case of $t_{\text {pilot }}=0.45 \mathrm{~ms}$. This is potentially attributed to the effects of more diesel-CH4 clouds due to the addition of pilot amount. In the case of $t_{\text {pilot }}=0.70 \mathrm{~ms}$, more diesel is injected into the cylinder, which leads to stronger luminous soot emission, futher increasing the luminous intensity in-cylinder.However, the fluctuations of sooty flame is less than the case of $t_{\text {pilot }}=0.6 \mathrm{~ms}$. This is because the longer injection duration of pilot diesel leads to more stable spray and combustion flame. It can be seen that the stable combustion occurs after 10 CAD ATDC.
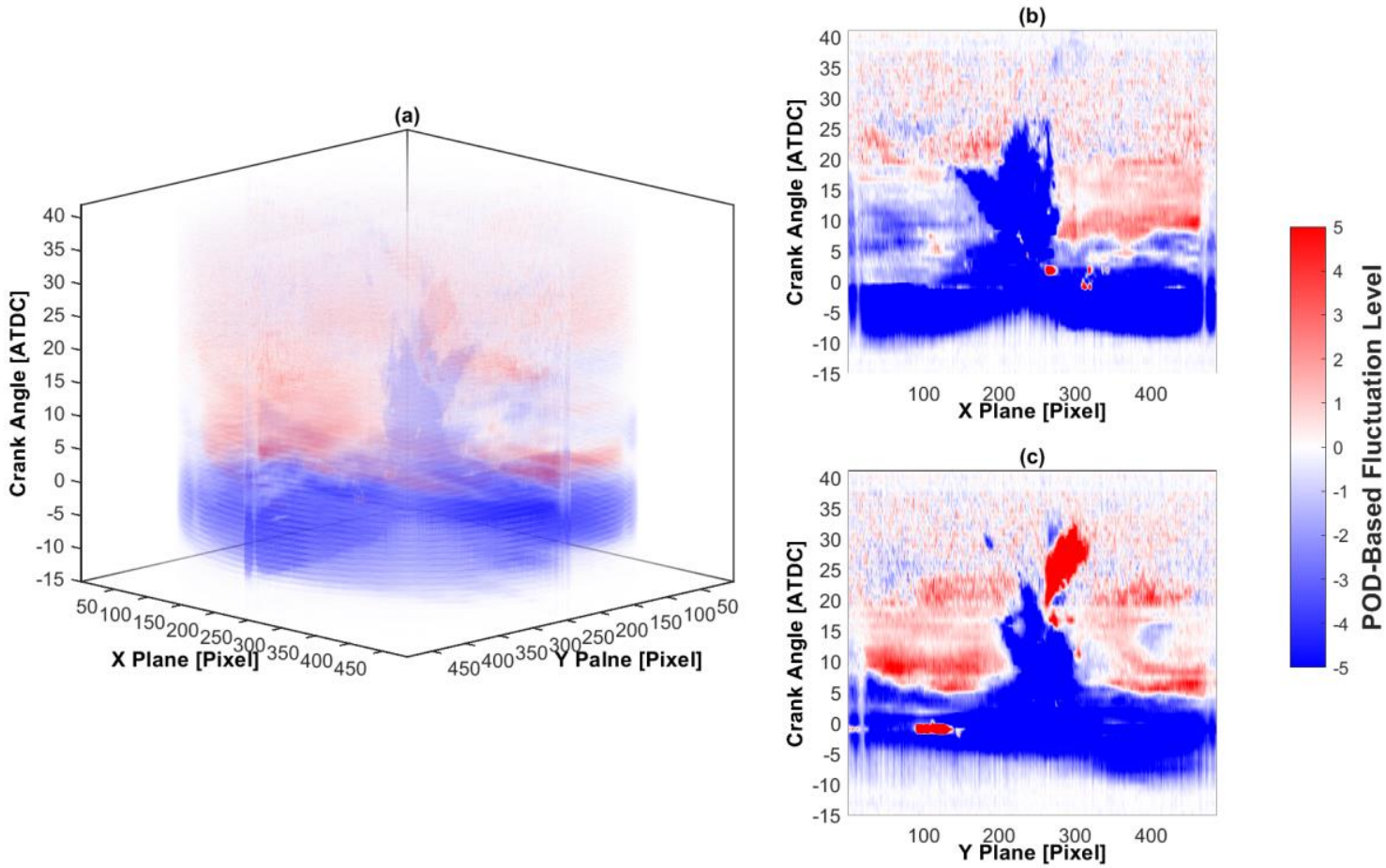

Fig.17 Temporal-spatial features of POD-based fluctuations. (a) 4-D plot; (b) X-plane; (c) Y-plane at condition of $\lambda_{\mathrm{CH} 4}=2.0, t_{\text {pilot }}=0.45 \mathrm{~ms}$ and $T_{\text {air }}=298 \mathrm{~K}$ 

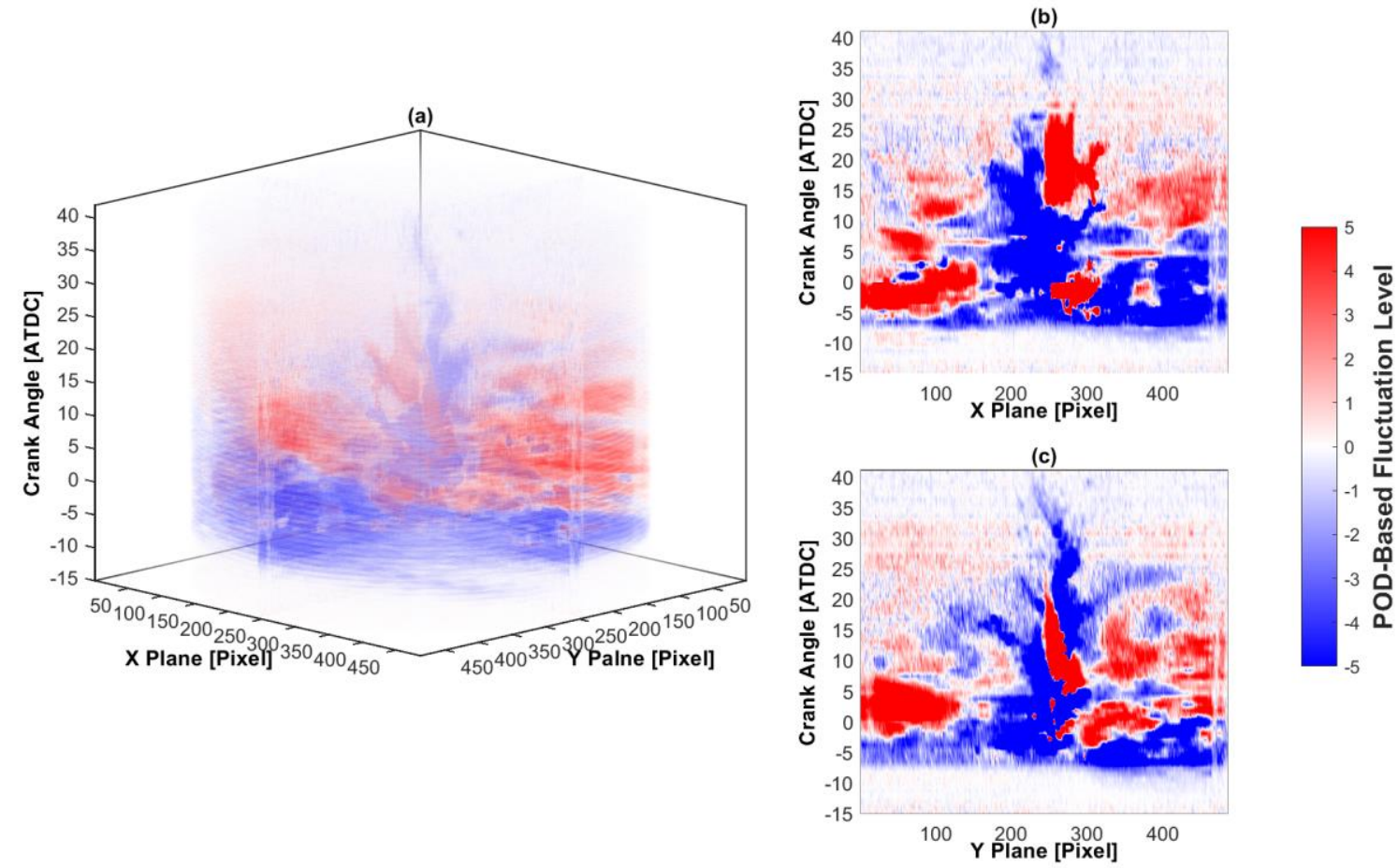

Fig.18 Temporal-spatial features of POD-based fluctuations. (a) 4-D plot; (b) X-plane; (c) Y-plane at condition of $\lambda_{\mathrm{CH} 4}=2.0, t_{\text {pilot }}=0.6 \mathrm{~ms}$ and $T_{\text {air }}=298 \mathrm{~K}$
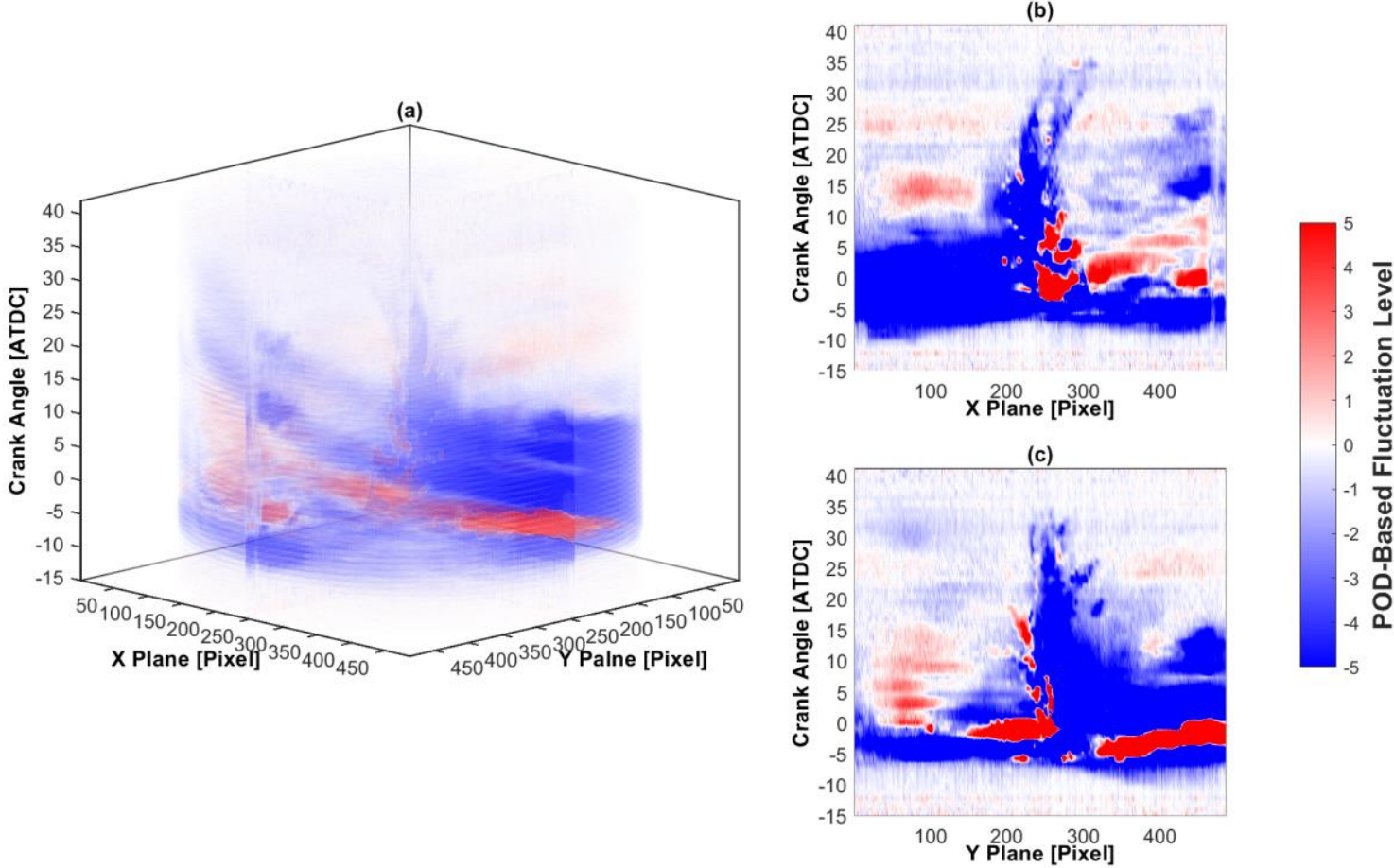

Fig.19 Temporal-spatial features of POD-based fluctuations. (a) 4-D plot; (b) X-plane; (c) Y-plane at condition of $\lambda_{\mathrm{CH} 4}=2.0, t_{\text {pilot }}=0.7 \mathrm{~ms}$ and $T_{\text {air }}=298 \mathrm{~K}$ 


\subsection{Effect of charge air temperature on CCV}

The effect of charge air temperature on dual-fuel combustion is examined by varying the intake air temperatures at $\lambda_{\mathrm{CH} 4}=2.0$ and pilot fuel duration $\mathrm{t}=0.45 \mathrm{~ms}$. Fig. 20 (a) demonstrates the global intensity (bottom) and intensity-based COV (top) with different charge air temperature ( $T_{\text {air }}$. The global intensity displays a monotonic increase with the increase of $T_{\text {air, }}$, which implies that the increase of $T_{\text {air }}$ could influence the maximum combustion temperature during compression stroke. The intensity of natural luminosity is strongly related to the maximum combustion temperature [49]. Moreover, the increase of $T_{\text {air }}$ improves the reactivity of the CH4-air mixture helping overcome the bulk quenching phenomena and escape the flammability limit under ultra-lean condition. It can be observed that high $T_{\text {air }}$ advances the appearance of the intensity-based COV due to the positive effect on low-temperature ignition. It is interesting to note that the intensity-based COV shows the highest peak at $T_{\text {air }}=318 \mathrm{~K}$.

Fig.20(b) demonstrates the effect of charge air temperature on the RGB intensity and color-intensity based COV. The blue channel shows highest intensity and longest duration due to a dominant lowtemperature $\mathrm{CH} 4$ flame. The RGB intensity indicates that the $T_{\text {air }}=318 \mathrm{~K}$ shows intensity similar to $T_{\text {air }}=298 \mathrm{~K}$ at premixed combustion stage, while exhibiting intensity similar to $T_{\text {air }}=328 \mathrm{~K}$ at diffusion combustion stage. The similar intensity in lower $T_{\text {air }}$ can be attributed to the bulk quenching phenomena and flammability limit in ultra-lean combustion. When the $T_{\text {air }}$ is not high enough to overcome the bulk quenching phenomena and escape the flammability limit, there are marginal differences in luminous intensity. However, $T_{\text {air }}$ has minor effects on the luminous intensity in diffusion combustion once the $T_{\text {air }}$ overcomes the bulk quenching phenomena and escape the flammability limit. The COVs in green and blue channels show the similar timing of the appearance of cyclic variations, and appearance of cyclic variation in the red channel occurs slightly later. The increase in the $T_{\text {air }}$ advances the COVs in all RGB channels, which corresponds to the shorter IDT.

Fig.20(c) shows the effect of charge air temperature on cylinder pressure (bottom) and HRR (top). The increase in $T_{\text {air }}$ improves the reactivity of the mixture, which results in advance the ignition. However, shorter ignition delay reduces the mixing time for diesel-CH4-air, which lowers the peak of HRR with high charge air temperature.

The comparison of the effect of $T_{\text {air }}$ on CCVs is shown in Fig.20(d). The POD-based and intensity-based COVs exhibit similar trends in cyclic variations for all charge air temperatures, the pressure-based COV also shows similar trends of cyclic variations with the COVs in luminosity field at $T_{\text {air }}=298 \mathrm{~K}$ and $T_{\text {air }}$ $=328 \mathrm{~K}$. However, the opposite trends of the peak COVs value at $T_{\text {air }}=318 \mathrm{~K}$ can be observed in pressure-based COV and COVs in luminosity field. As previously explained, it is represented that there are fewer CCVs in thermodynamics, while more CCVs in the luminosity field. The increase in $T_{\text {air }}$ advances the occurrence of CCVs, which can be observed in pressure-based COV and COVs in the luminosity field. An increase in $T_{\text {air }}$ increases the Arrhenius rate of pre-ignition intermediary chemical reactions of diesel pilot and surrounding $\mathrm{CH} 4$-air mixture, and as a consequence, results in forward ignition and cyclic variations. 


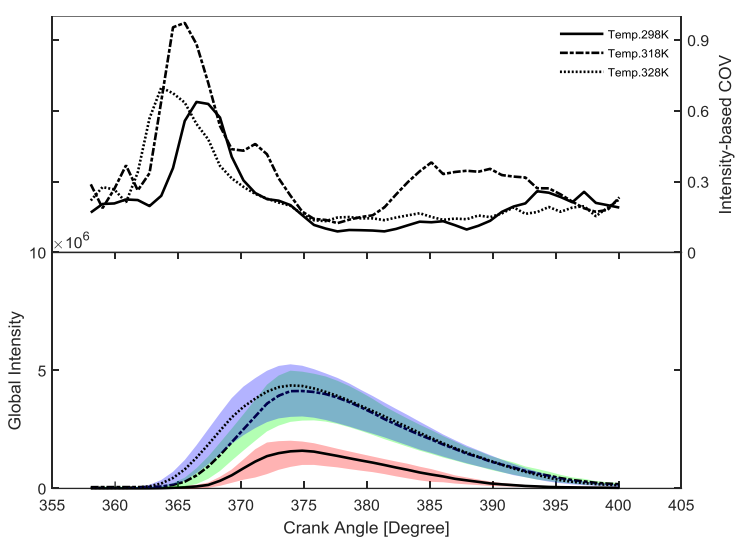

(a)

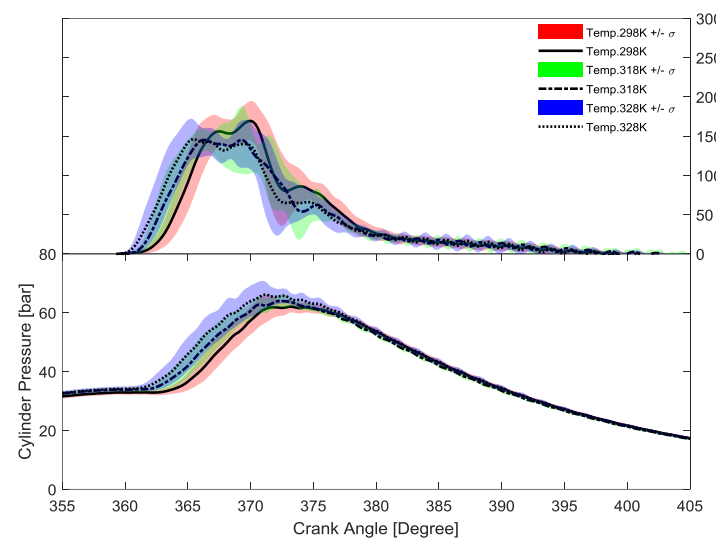

(c)

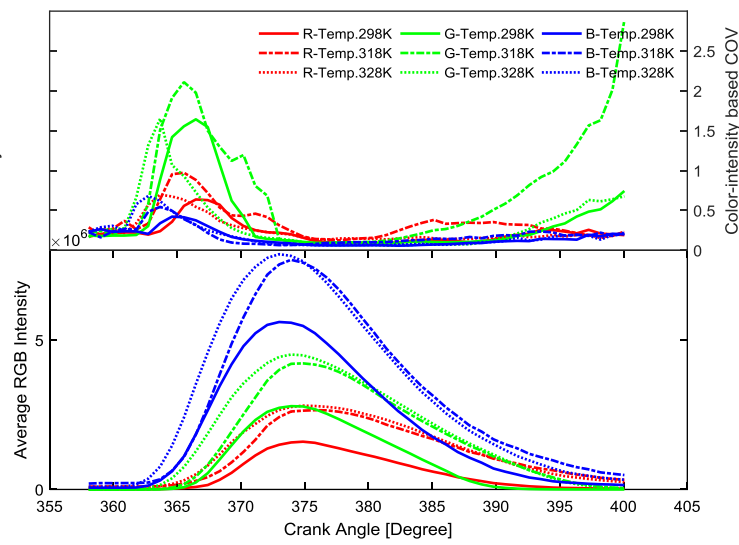

(b)

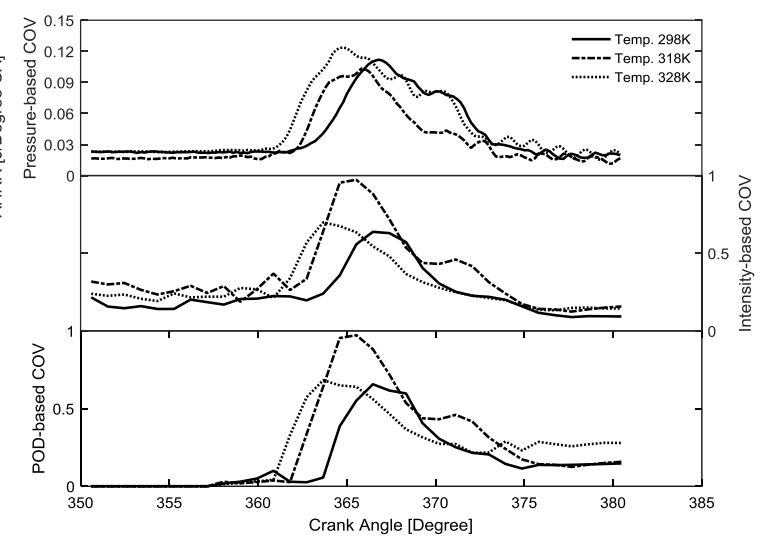

(d)

Fig.20 Effect of charge air temperature on CCVs. (a) global intensity and intensity-based COV; (b) color intensity and color-intensity based COV (R-, G-, B- represent the intensity or COV in red, green and blue channel, respctively); (c) cylinder pressure and HRR; (d) comparison of the COVs based on

POD, global intensity and cylinder pressure

Fig.21-23 depict the temeporal-spatial features of POD-based fluactuation level with different $T_{\text {air. }}$ This crank angle is selected as representative of high POD-based COV. At low temeprature condition $\left(T_{\text {air }}=\right.$ $298 \mathrm{~K})$, as previous explanation, the "random" small pieces of fluctuation can be observed, the "red" can be observed near the nozzle to shows no pattern of the dribbling over cycles. The premixed flame has more contributions on the fluctuations, which display more "blue" during main combustion. In the case of $T_{\text {air }}=318 \mathrm{~K}$, the duration of premixed combustion is shorter than the case of $T_{\text {air }}=298 \mathrm{~K}$, which is from 5 CAD BTDC to 10 CAD ATDC. The fluctuation of sooty flame starts at right of TDC, and then gradually dominate the full cylinder untile 20 CAD ATDC. Owing to the higher charge air temperature the chemical reaction is enhaced, which results in more extensive spatial distibution of the louminous intensity, and more fluactuation coused by sooty flame can be observed and the fluacutation level is higher. Therefore, it can be concluded that the sooty flame has more contribution on the fluactuation at higher charge air conditions. It is worth to note that the fluctuation level of premixed flame is lower than the case of $T_{\text {air }}=318 \mathrm{~K}$. In the case of $T_{\text {air }}=328 \mathrm{~K}$, the charge air temeprature is even higher, the luminous intensity is also stronger due to the enhancement of chemical reaction. However, the fluctuations levels of sooty flame and premixed flame are less than the case of $T_{\text {air }}=318 \mathrm{~K}$. This phenomenon can be explained by the inhibitive effects on fluctuations due to the combustion is faster and more stable. 

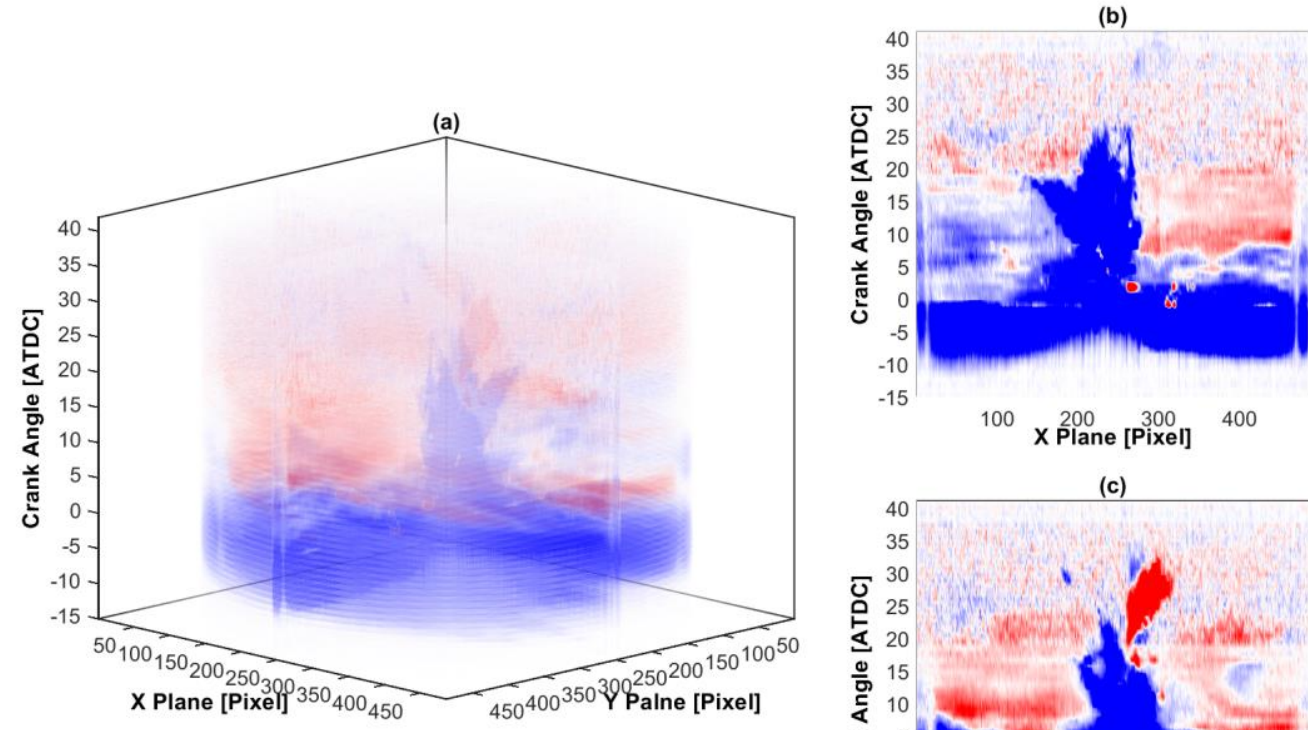

(c)
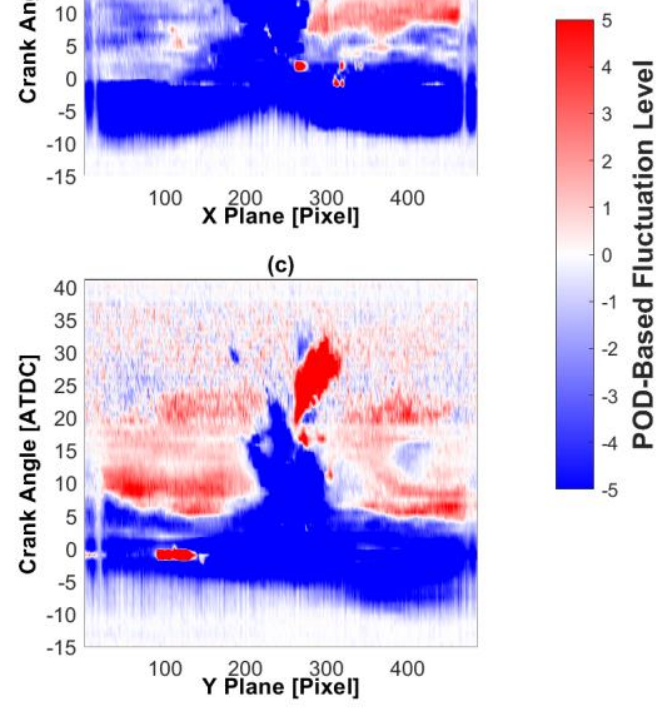

Fig.21 Temporal-spatial features of POD-based fluctuations. (a) 4-D plot; (b) X-plane; (c) Y-plane at condition of $\lambda_{\mathrm{CH} 4}=2.0, t_{\text {pilot }}=0.45 \mathrm{~ms}$ and $T_{\text {air }}=298 \mathrm{~K}$
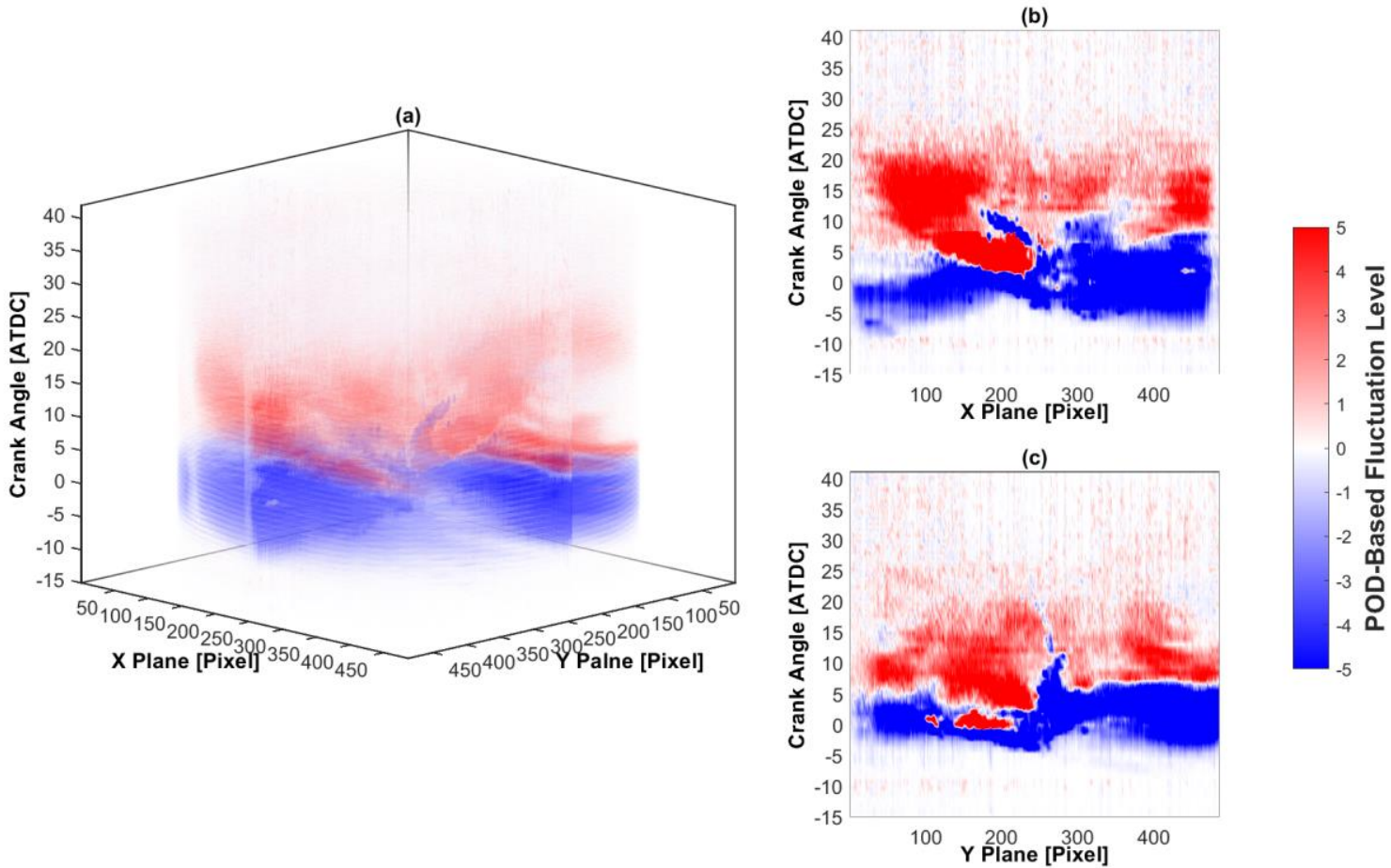

Fig.22 Temporal-spatial features of POD-based fluctuations. (a) 4-D plot; (b) X-plane; (c) Y-plane at condition of $\lambda_{\mathrm{CH} 4}=2.0, t_{\text {pilot }}=0.45 \mathrm{~ms}$ and $T_{\text {air }}=318 \mathrm{~K}$ 

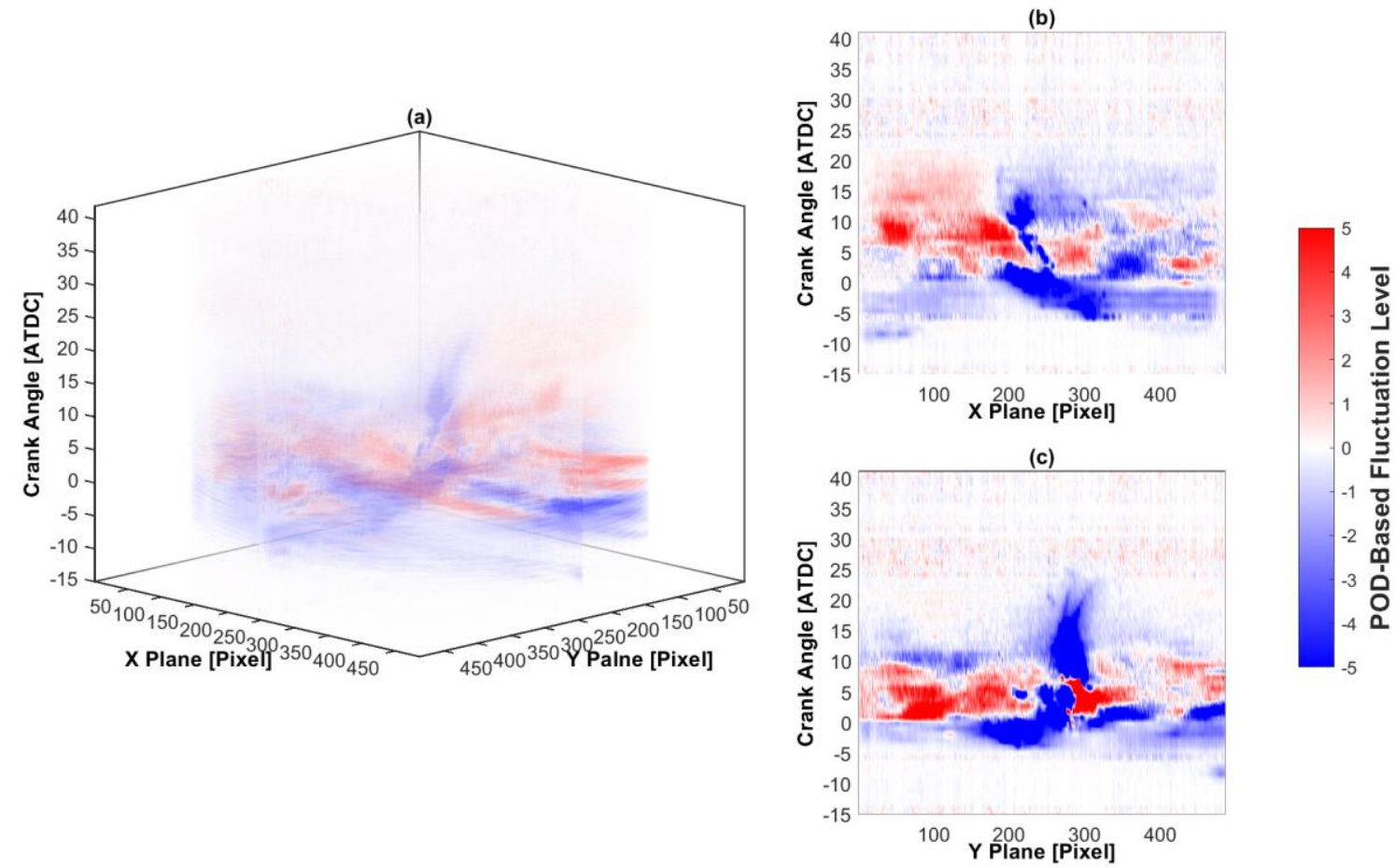

Fig.23 Temporal-spatial features of POD-based fluctuations. (a) 4-D plot; (b) X-plane; (c) Y-plane at condition of $\lambda_{\mathrm{CH} 4}=2.0, t_{\text {pilot }}=0.45 \mathrm{~ms}$ and $T_{\text {air }}=328 \mathrm{~K}$

\section{Conclusions}

This work aims to improve the understanding of the sources of CCV in DF combustion. Measurements based on high-speed color camera were conducted in an optically accessible compression ignition engine fueled with CH4 (primary fuel) and diesel (pilot fuel). The effects of CH4 lambda, pilot fuel duration and charge air temperature on CCVs were analyzed based on cylinder pressure, global intensity and POD. The major conclusions regarding the CCVs of DF combustion are drawn as follows:

(1) A POD based method has been implemented to increase the understanding of CCVs in the luminosity field of DF combustion. A spatial structure of the fluctuation in the luminosity field can be separated into coherent and incoherent parts, to gain more information on the underlying turbulent flow.

(2) A statistical method was adopted to further discriminate the coherent from the incoherent fluctuations. The results show that a spatial structure of the coherent part of fluctuation can represent most of the fluctuations, while the incoherent part of the fluctuation can be identified as the "random" spatial distribution of the luminous intensity. This provides a method for recognizing the location of high fluctuation intensity regions in the cylinder.

(3) The addition of CH4 considerably retards the ignition delay, which results in a later appearance of COVs. The earliest and highest green-intensity based COV imply that $\lambda_{\mathrm{CH} 4}$ has a significant effect on low-temperature ignition. Significant differences of COVs can be observed between pressurebased and luminosity-based COVs, which can be attributed to the different sensitivities of CCVs in thermodynamics and the luminosity field. 
(4) The ignition characteristics of pilot fuel play a crucial role in the stability of the lean-burn DF combustion. The addition of pilot fuel has an inhibitive effect on the cyclic variabilities in the luminosity field. However, similar pressure-based COVs at $t_{\text {pilot }}=0.45$ and $0.60 \mathrm{~ms}$ show that there is a minor effect of $t_{\text {pilot }}$ on CCVs in thermodynamics due to a low proportion of diesel cloud volume in the cylinder. With further increase in the $t_{\text {pilot, }}$, the decrease in the pressure-based COV becomes discernable.

(5) Under ultra-lean conditions, the increase in charge air temperature is helpful to overcome the bulk quenching phenomena and escape the flammability limit. However, there is a critical point for $T_{\text {air. }}$. In the current study, the critical value of $T_{\text {air }}$ is near $318 \mathrm{~K}$, because it shows the highest COVs in the luminosity field and the lowest pressure-based COV. This implies that the critical $T_{\text {air }}$ has an inhibitive effect on CCVs in thermodynamics and a promotion effect on CCVs in the luminosity field.

\section{Acknowledgments}

The financial support from Aalto University, School of Engineering (Department of Mechanical Engineering) and Finnish Academy project (Grant No. 297248) are acknowledged.

\section{References}

[1] JOHN W. DAILY (1988) Cycle-to-Cycle Variations: A Chaotic Process?, Combustion Science and Technology, 1988(57): 149-162

[2] M. Y. E. Selim, "Sensitivity of dual fuel engine combustion and knocking limits to gaseous fuel composition," Energy Conversion and Management, 2004(45): 411-425.

[3]Yang Z, Steffen T, Stobart R. Disturbance sources in the diesel engine combustion process. SAE International; 2013. 2013-01-0318.

[4] Murayama T, Yamada T, Miyamoto N, Chikahisa T. Nature and reduction of cycle-to-cycle combustion engine with ethanol-diesel fuel blends. SAE International; 1983. 831352.

[5] Bittle J, Knight B, Jacobs T. Biodiesel effects on cycle-to-cycle variability of combustion characteristics in a common-rail medium-duty diesel engine. SAE International; 2010. 2010-01-0867

[6] Panagiotis Kyrtatos, Clemens Brückner, Konstantinos Boulouchos. Cycle-to-cycle variations in diesel engines. Applied Energy 171 (2016) 120-132.

[7]Heywood JB. Internal combustion engine fundamentals. New York: McGraw-Hill; 1988.

[8] Pera C, Knop V, Reveillon J. Influence of flow and ignition fluctuations on cycleto-cycle variations in early flame kernel growth. Proc Combust Inst 2015(35):2897-905.

[9]Zhang HG, Han XJ, Yao BF, Li GX. Study on the effect of engine operation parameters on cyclic combustion variations and correlation coefficient between the pressure-related parameters of a CNG engine. Applied Energy 2013(104):992-1002.

[10] Rashidi M. The nature of cycle-by-cycle variation in the SI engine from high speed photographs. Combustion and Flame 1981(42):111-22.

[11] Bizon K, Continillo G, Lombardi S, Sementa P, Vaglieco BM. Independent component analysis of cycle resolved combustion images from a spark ignition optical engine. Combustion and Flame 2016(163):258-69. 
[12]Curto-Risso PL, Medina A, Calvo Hernández A, Guzmán-Vargas L, Angulo-Brown F. On cycleto-cycle heat release variations in a simulated spark ignition heat engine. Applied Energy 2011(88):1557-67.

[13] Koch J, Schmitt M, Wright YM, Steurs K, Boulouchos K. LES multi-cycle analysis of the combustion process in a small SI engine. SAE Int J Eng 2014 (7):269-85.

[14] Vermorel O, Richard S, Colin O, Angelberger C, Benkenida A, Veynante D. Towards the understanding of cyclic variability in a spark ignited engine using multi-cycle LES. Combust Flame 2009(156):1525-41.

[15] M. Schmitt, C. E. Frouzakis, Y. M. Wright, A. G. Tomboulides, and K. Boulouchos. Investigation of cycle-to-cycle variations in an engine-like geometry. Physics of Fluids 26, 035105, 2014.

[16] M. Ghaderi Masouleha, K. Keskinena, O. Kaario, et al. Flow and thermal field effects on cycle-tocycle variation of combustion: scale-resolving simulation in a spark ignited simplified engine configuration. Applied Energy 230 (2018) 486-505.

[17] Zhong L, Singh IP, Han J, Lai M-C, Henein NA, Bryzik W. Effect of cycle-to-cycle variation in the injection pressure in a common rail diesel injection system on engine performance. SAE International; 2003. 2003-01-0699.

[18] You-cheng S, Min X, Yong G, Yi C, Lei S, Kang-yao D. Effects of injection pressure, exhaust gas recirculation and intake pressure on the cycle-to-cycle variations of HCCI combustion. J Energy Inst 2015.

[19] You-cheng S, Min X, Yong G, Yi C, Lei S, Kang-yao D. Effects of injection pressure, exhaust gas recirculation and intake pressure on the cycle-to-cycle variations of HCCI combustion. J Energy Inst 2015.

[20] ShyamSundar Pasunurthi and Ravichandra Jupudi. Cycle to Cycle Variation Study in a Dual Fuel Operated Engine. SAE International, 2017-01-0772

[21] Pera C, Knop V, Reveillon J. Influence of flow and ignition fluctuations on cycleto-cycle variations in early flame kernel growth. Proc Combust Inst 2015(35):2897-905.

[22] Curto-Risso PL, Medina A, Calvo Hernández A, Guzmán-Vargas L, Angulo- Brown F. On cycleto-cycle heat release variations in a simulated spark ignition heat engine. Appl Energy 2011(88):155767.

[23] K. Bizon, S. Lombardi, G. Continillo, E. Mancaruso, B.M. Vaglieco, Analysis of Diesel engine combustion using imaging and independent component analysis, Proc. Combust. Inst. 2013 (34) 29212931.

[24] Bittle J, Knight B, Jacobs T. Biodiesel effects on cycle-to-cycle variability of combustion characteristics in a common-rail medium-duty diesel engine. SAE International; 2010-01-0867.

[25] You-cheng S, Min X, Yong G, Yi C, Lei S, Kang-yao D. Effects of injection pressure, exhaust gas recirculation and intake pressure on the cycle-to-cycle variations of HCCI combustion. J Energy Inst 2015.

[26] Maurya RK, Agarwal AK. Experimental investigation on the effect of intake air temperature and air-fuel ratio on cycle-to-cycle variations of HCCI combustion and performance parameters. Appl Energy 2011(88): 1153-63.

[27] Maurya RK, Agarwal AK. Experimental investigation of cyclic variations in HCCI combustion parameters for gasoline like fuels using statistical methods. Appl Energy 2013(111): 310-23. 
[28] Jupudi, R., Finney, C., Primus, R., Wijeyakulasuriya, S. et al., Application of High Performance Computing for Simulating Cycle-to-Cycle Variation in Dual-Fuel Combustion Engines, SAE Technical Paper 2016-01-0798.

[29] Widodo Budi. Santoso, Rosli Abu. Bakar, Sugeng. Ariyono, et al. Study of Cyclic Variability in Diesel-Hydrogen Dual Fuel Engine Combustion. International Journal of Mechanical \& Mechatronics Engineering IJMME-IJENS 2012(12): 52-56.

[30] ShyamSundar Pasunurthi, Ravichandra Jupudi, Sameera Wijeyakulasuriya, et al. Cycle to Cycle Variation Study in a Dual Fuel Operated Engine. SAE International; 2017-01-0772.

[31] Ying Wang, Fan Xiao, Yuwei Zhao. Study on cycle-by-cycle variations in a diesel engine with dimethyl ether as port premixing fuel. Applied Energy, 2015 (143): 58-70.

[32] Tong Luo, Su Jiang, Adams Moro, et al. Measurement and validation of hole-to-hole fuel injection rate from a diesel injector. Flow Measurement and Instrumentation, 2018(61):66-78

[33] Gaetan Kerschen, Jean-Claude Golinval, Alexander F. Vakakis, et al. The Method of Proper Orthogonal Decomposition for Dynamical Characterization and Order Reduction of Mechanical Systems: An Overview. Nonlinear Dynamics (2005) 41: 147-169

[34] Jean Rabault, Julie A.Verneta, Björn Lindgren, et al. A study using PIV of the intake flow in a diesel engine cylinder. International Journal of Heat and Fluid Flow 2016(62A): 56-67.

[35] K. Bizon, G. Continillo, E. Mancaruso, et al. POD-based analysis of combustion images in optically accessible engines. Combustion and Flame 2010 (157): 632-640

[36] K. Bizon, G. Continillo, K.C. Leistner, et al. POD-based analysis of cycle-to-cycle variations in an optically accessible diesel engine. Proceedings of the Combustion Institute 2009 (32): 2809-2816.

[37] Katarzyna Bizon, Gaetano Continillo, Simone Lombardi, et al. Independent component analysis of cycle resolved combustion images from a spark ignition optical engine. Combustion and Flame 2016 (163): 258-269.

[38] A.G. Charalambidesa, S. Sahub, Y. Hardalupasc, et al. Evaluation of Homogeneous Charge Compression Ignition (HCCI) autoignition development through chemiluminescence imaging and Proper Orthogonal Decomposition, Applied Energy 2018(210): 288-302

[39] M.J.Zimoń, J.M.Reese and D.R.Emerson. A novel coupling of noise reduction algorithms for particle flow simulations. Journal of Computational Physics 2016(321): 169-190.

[40] Jozef Jarosinski; Bernard Veyssiere. Combustion Phenomena: Selected Mechanisms of Flame Formation, Propagation and Extinction. CRC Press; 2009.

[41] Chun LouChen ChenYiPeng Sun, et al. Review of soot measurement in hydrocarbon-air flames. Science China Technological Sciences 2010 (53): 2129-2141.

[42] Ahmad, Z., Aryal, J., Ranta, O., Kaario, O. et al., An Optical Characterization of Dual-Fuel Combustion in a Heavy-Duty Diesel Engine, SAE Technical Paper 2018-01-0252, 2018.

[43] Aleš Srna, Michele Bolla, Yuri M. Wright, et al. Effect of methane on pilot-fuel auto-ignition in dual-fuel engines. Proceedings of the Combustion Institute 37 (2019) 4741-4749.

[44] M. Loève, Probability Theory, fourth ed., vol. 2, Springer-Verlag, Berlin, Germany, 1978.

[45] F Migliorini, S Maffi, S De Iuliis and G Zizak. Analysis of chemiluminescence measurements by grey-scale ICCD and colour digital cameras. Meas. Sci. Technol. 2014 (25): 055202 (8pp). 
[46] Avinash K Agarwal, Ashok Pandey, Ashwani K. Gupta, et al. Novel Combustion Concepts for Sustainable Energy Development. Springer; 2014.

[47] Miqdam Tariq Chaichan. Combustion of Dual Fuel Type Natural Gas/Liquid Diesel Fuel in Compression Ignition Engine. IOSR Journal of Mechanical and Civil Engineering (IOSR-JMCE) 2014(11): 48-58.

[48] G.H.Abd All, H.A.Soliman, O.A.Badr. Effect of Pilot Fuel Quantity on the Performance of a Dual Fuel Engine. Energy Conversion and Management 2000(41): 559-572.

[49] M.Alfè, B.ApicellaaJ.-N.Rouzaud, et al. The effect of temperature on soot properties in premixed methane flames. Combustion and Flame 2010(157): 1959-1965. 